\title{
A Comparative Frequency Analysis of Maximum Daily Rainfall for a SE Asian Region under Current and Future Climate Conditions
}

\author{
Velautham Daksiya, ${ }^{1,2}$ Pradeep Mandapaka, ${ }^{3}$ and Edmond Y. M. Lo ${ }^{3,4}$ \\ ${ }^{1}$ Environmental Process Modelling Centre, Nanyang Environmental \& Water Research Institute, \\ Nanyang Technological University, Singapore \\ ${ }^{2}$ Interdisciplinary Graduate School, Nanyang Technological University, Singapore \\ ${ }^{3}$ Institute of Catastrophe Risk Management, Nanyang Technological University, Singapore \\ ${ }^{4}$ School of Civil and Environmental Engineering, Nanyang Technological University, Singapore \\ Correspondence should be addressed to Velautham Daksiya; daksiya001@e.ntu.edu.sg
}

Received 4 November 2016; Revised 28 December 2016; Accepted 18 January 2017; Published 15 February 2017

Academic Editor: Momcilo Markus

Copyright (C) 2017 Velautham Daksiya et al. This is an open access article distributed under the Creative Commons Attribution License, which permits unrestricted use, distribution, and reproduction in any medium, provided the original work is properly cited.

\begin{abstract}
The impact of changing climate on the frequency of daily rainfall extremes in Jakarta, Indonesia, is analysed and quantified. The study used three different models to assess the changes in rainfall characteristics. The first method involves the use of the weather generator LARS-WG to quantify changes between historical and future daily rainfall maxima. The second approach consists of statistically downscaling general circulation model (GCM) output based on historical empirical relationships between GCM output and station rainfall. Lastly, the study employed recent statistically downscaled global gridded rainfall projections to characterize climate change impact rainfall structure. Both annual and seasonal rainfall extremes are studied. The results show significant changes in annual maximum daily rainfall, with an average increase as high as $20 \%$ in the 100 -year return period daily rainfall. The uncertainty arising from the use of different GCMs was found to be much larger than the uncertainty from the emission scenarios. Furthermore, the annual and wet seasonal analyses exhibit similar behaviors with increased future rainfall, but the dry season is not consistent across the models. The GCM uncertainty is larger in the dry season compared to annual and wet season.
\end{abstract}

\section{Introduction}

The increase in the atmospheric concentrations of greenhouse gases and the resulting global warming is expected to cause significant changes in the precipitation structure (e.g., amount, extremes, and spatial variability) [1-6]. Many studies have analysed historical rainfall and future climate projections thereof from General Circulation Models (GCM) for predefined climate scenarios and quantified the changes in precipitation characteristics at global and regional scales [7-10]. However, given the large variability in precipitation in tropical regions and that the spatial resolution of GCM output is quite coarse $\left(1^{\circ}-2.5^{\circ}\right)$ [11], the GCM outputs are required to be scaled down to local scales using downscaling techniques.

There are two main approaches for downscaling: statistical and dynamical. Statistical downscaling techniques use empirical relationships between large-scale climate predictors from GCMs and local-scale predictands to obtain station-level variables of interest $[12,13]$. Conversely dynamical downscaling techniques employ regional climate models with GCM output variables as boundary conditions to produce higher resolution (e.g., $25 \mathrm{~km}$ ) output $[14,15]$. The statistical downscaling approach is widely used because of its easy implementation, low computational effort, and ability to provide point-scale output $[16,17]$. Several statistical downscaling models have been developed in the last few decades and can be broadly classified as regression models, weather typing schemes, and weather generators [14]. Some widely employed models include the Weather Generator (WGEN), the Long Ashton Research Station-Weather Generator (LARS-WG), and the Statistical Downscaling Model (SDSM). Many recent studies have shown that these models 


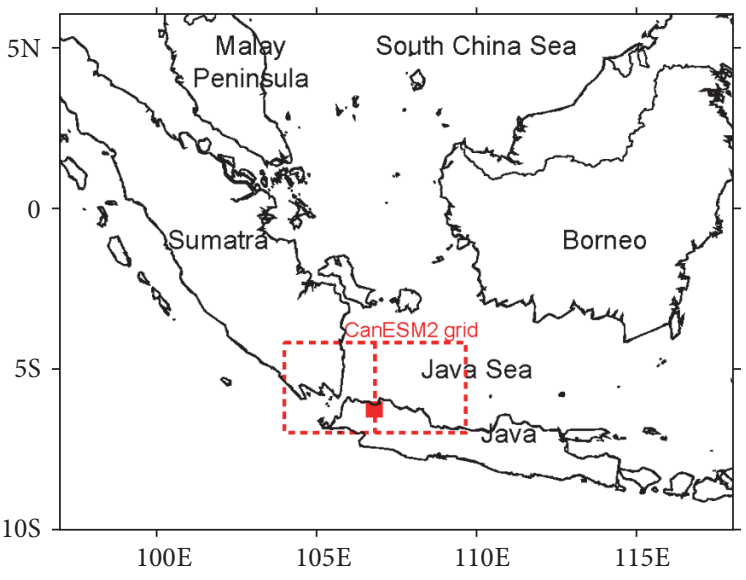

(a)

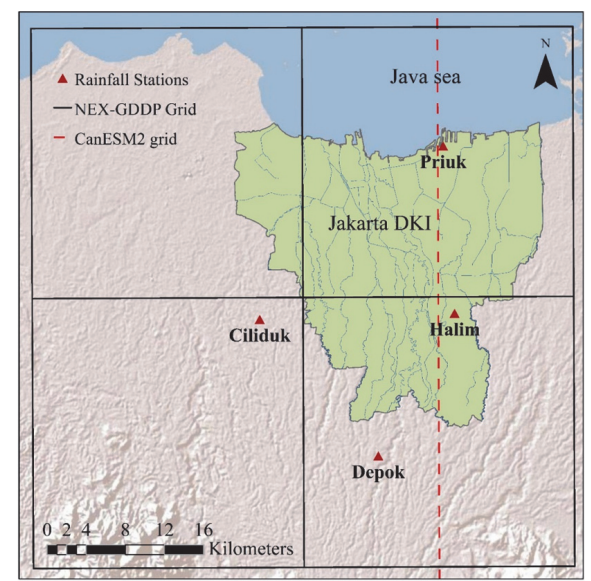

(b)

FIGURE 1: Map of the western Maritime Continent (a) showing the study area of Jakarta (filled red square) and CanESM2 grids and map of Jakarta (b) showing the rain gauges used and the NEX-GDDP grids. The red lines represent the CanESM2 grid. The green shaded area denotes the Jakarta DKI region.

are capable of providing station-level rainfall for different GCMs and future climate scenarios [12, 18, 19]. In addition to these downscaling models, high-resolution global gridded datasets for historical climate are available for hydrological studies. For future climate a very recent 2015 dataset is the NASA Earth Exchange Global Daily Downscaled Projections (NEX-GDDP) [20] for precipitation and temperature. This was used to characterize severity and extent of future drought in the Continental US [21].

In this paper, we analysed and quantified the impact of changing climate on the daily rainfall return period (RP) curves for a Southeast Asian region, that of Jakarta DKI (Daerah Khusus Ibukota or Special Capital Region), Indonesia. The study conducted a comparative analysis employing two models, LARS-WG and SDSM, and the downscaled gridded dataset, NEX-GDDP. Both annual and seasonal (wet, December-March, and dry, June-September) extremes are analysed. Jakarta was selected because it is highly vulnerable to riverine floods.

Jakarta DKI extends from $6.1^{\circ} \mathrm{S}$ to $6.5^{\circ} \mathrm{S}$ and $106.6^{\circ} \mathrm{E}$ to $107.0^{\circ} \mathrm{E}$ and spans an area of $642 \mathrm{~km}^{2}$ (Figure 1). It is reported that $40 \%$ percentage of Jakarta is below mean sea level [22]. The city frequently experiences severe flood events (e.g., in 2002, 2007, 2013, and 2014) with annual losses of USD 321 million $[23,24]$. The flood vulnerability of Jakarta is exacerbated by its population of 10 million people [25], rapid urbanization, and land subsidence [23]. While many studies have focused on characterizing the general climatology of Java Island in which Jakarta is located [26, 27] and quantified historical trends [28, 29], few have assessed the future changes in rainfall extremes in Jakarta [23, 30]. However such studies on local-scale changes in seasonal and annual rainfall maxima are needed for city planners in Jakarta and in similar flood-prone cities of South East Asia for purposes of flood control, water supply, and urban drainage.

The study framework is described in Section 2. The statistical models and datasets are described in Section 3.
The validation of statistical models and their application for future climate scenarios are discussed in Section 4, followed by concluding remarks in Section 5 .

\section{Study Framework}

The methodology comprises three components as shown in Figure 2. The first component involves the LARS-WG model. LARS-WG is a stochastic weather generator developed by Racsko et al. [31] and has undergone a series of improvements $[32,33]$. Given the daily time series of rainfall, temperature, and solar radiation at a particular station, the LARS-WG can generate synthetic daily rainfall series, whose statistics match well those of observed data $[34,35]$. Synthetic series can further be obtained for historical and future time periods. An advantage of using LARS-WG is that the information from $15 \mathrm{GCM}$ is embedded in the model, which allows an assessment of GCM model uncertainty. However, one drawback is that the latest version of LARS-WG (version 5.5) follows the IPCC Fourth Assessment Report (AR4) for future climate scenarios. More specifically, the synthetic rainfall series for a future time period can only be obtained for AR4 scenarios A1B, B1, and A2. It is noted that there are a few recent studies where LARS-WG is employed with the newer Representative Concentration Pathways (RCP) $[33,36]$ under the IPCC Fifth Assessment Report (AR5) and specifically using LARS-WG 6.0. However this version is still undergoing final tests (personal communication, Michael Semenov) and thus not used here.

SDSM, which forms the second component of the methodology, is used to examine changes in rainfall extremes under the newer RCP scenarios defined in AR5. However only one GCM, the second generation Canadian Earth System Model (CanESM2), is available in SDSM, and therefore climate model uncertainty cannot be assessed. The third and final component employs the NEX-GDDP dataset. The NEX-GDDP dataset consists of $0.25^{\circ}$ resolution gridded daily 


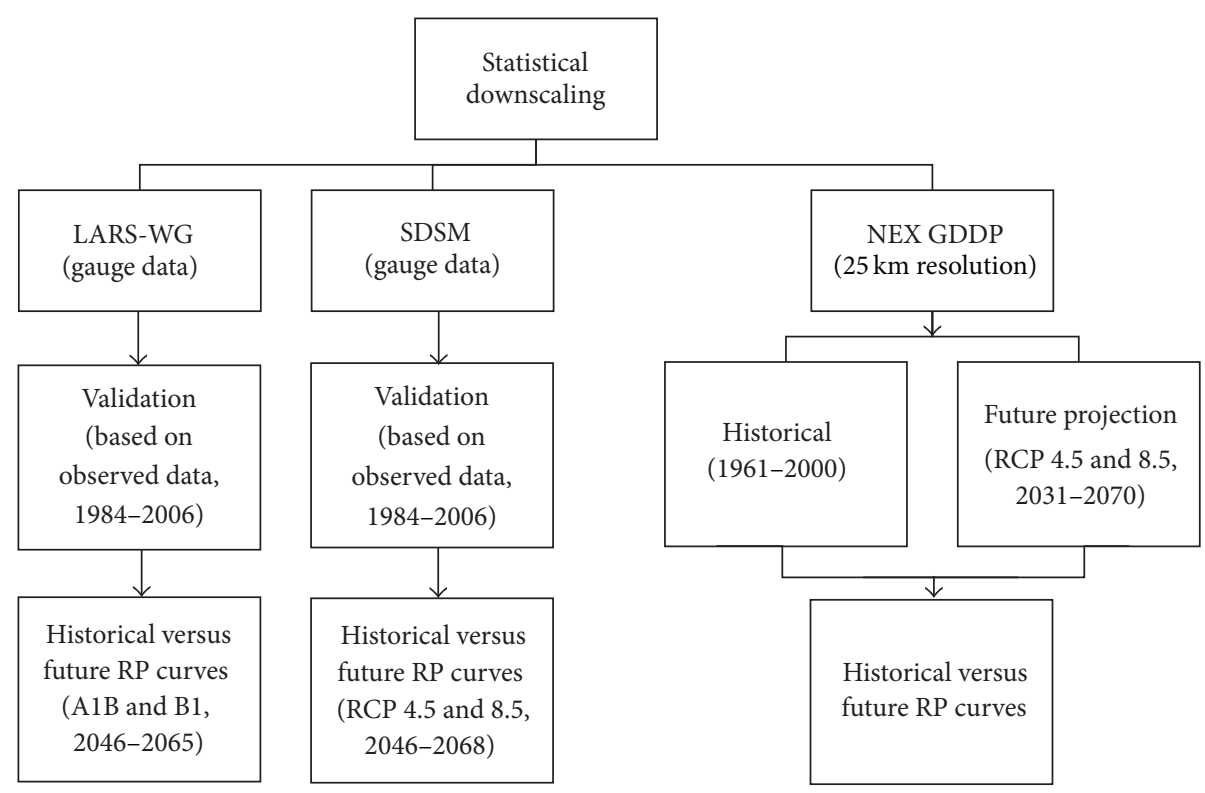

FIGURE 2: Methodology flowchart showing the framework comparing historical and future daily rainfall RP curves via three different components: LARS-WG, SDSM, and the NEX-GDDP gridded data.

projections of precipitation and temperature from 2006 to 2100 for 21 GCMs under AR5 RCP 4.5 and RCP 8.5 scenarios. The dataset also contain retrospective runs of $21 \mathrm{GCMs}$ for the time period of 1951-2005. To facilitate comparison with LARS-WG and SDSM analysis, we selected NEX-GDDP grids that cover the rain gauge locations of the study domain (Figure 2).

Consideration of different combinations of GCMs and future scenarios and downscaling methods as shown in Figure 2 allows us to investigate the relative importance of different sources of uncertainties in climate change impact studies. Characterization of the variability in the changes of future rainfall across these approaches will be useful in interpreting climate change impacts.

\section{Data and Models}

Observed daily rainfall data from four gauging stations (Halim, Priuk, Ciliduk, and Depok) for the period of 19842006 are available [37] and used for this study (Figure 1). Based on the recorded data, the regional averages of annual rainfall and annual maximum daily rainfall are $1983 \mathrm{~mm}$ and $112 \mathrm{~mm} /$ day, respectively.

3.1. LARS-WG Model Runs. LARS-WG requires input weather variables such as the solar radiation and the maximum and minimum temperature. Data for the four stations are obtained from the Global Weather Data for Soil and Water Assessment Tool (SWAT) website (https://globalweather.tamu.edu/). The LARS-WG model involves three major steps: (i) determining statistical characteristics of observed data, (ii) comparing statistical characteristics of observed data and the generated data, and (iii) generating synthetic data based on statistical characteristics of the observed data [38]. For the future time period, the model generates synthetic time series based on a change factor approach. The latest version available, LARS-WG 5.5, is capable of generating future rainfall with 15 GCMs under AR4 emission scenarios (A1B, B1, and A2) for three future time periods 2011-2030, 2046-2065, and 2081-2099. The emission scenario A1B is available in all 15 GCMs and B1 and A2 are available in 11 and 9 GCMs, respectively (see Table 1 in [34]).

For this study, we generated 100 independent sequences of synthetic daily rainfall, each with the length of 23 years using observations from 1984 to 2006. Similarly, one hundred, 23year-long sequences of future rainfall series were generated for emission scenarios A1B (15 GCMs) and B1 (11 GCMs) over the period of 2046-2065. The length of each sequence was chosen to match with the length of the observed record, and 100 sequences were generated in order to characterize the uncertainty.

3.2. SDSM Model Runs. SDSM is a combination of multiple linear regression and stochastic weather generator developed by Wilby et al. [17] and has undergone number of improvements. SDSM is capable of generating future rainfall time series with AR5 emission scenarios [2]. This study used SDSM 4.2.9 to generate the future daily rainfall under the RCP 4.5 and RCP 8.5 as available with the CanESM2 GCM. SDSM needs two types of input daily data: (1) the local predictands of interest (daily rainfall in our case) and (2) the large-scale regional predictors from the GCM grid box that covers the study area. CanESM2 predictors (Table 1) were obtained from Canadian Climate Data and Scenarios for each station from the corresponding grid box (http://ccds-dscc.ec.gc.ca/?page=pred-canesm2). An empirical relationship between the predictors and the predictand is then used to obtain station-level daily rainfall series. 
TABLE 1: CanESM2 predictors used in screening process.

\begin{tabular}{lc}
\hline Predictor & Description \\
\hline Ceshmslpgl & Mean sea level pressure \\
ceshp1_fpgl & $1000 \mathrm{hPa}$ wind speed \\
ceshp1_upgl & $1000 \mathrm{hPa}$ zonal velocity \\
ceshp1_vpgl & $1000 \mathrm{hPa}$ meridional velocity \\
ceshp1_zpgl & $1000 \mathrm{hPa}$ vorticity \\
ceshp1thpgl & $1000 \mathrm{hPa}$ wind direction \\
ceshplzhpgl & $1000 \mathrm{hPa}$ divergence \\
ceshp5_fpgl & $500 \mathrm{hPa}$ wind speed \\
ceshp5_upgl & $500 \mathrm{hPa}$ zonal velocity \\
ceshp5_vpgl & $500 \mathrm{hPa}$ meridional velocity \\
ceshp5_zpgl & $500 \mathrm{hPa}$ vorticity \\
ceshp5thpgl & $500 \mathrm{hPa}$ wind direction \\
ceshp5zhpgl & $500 \mathrm{hPa}$ divergence \\
ceshp8_fpgl & $800 \mathrm{hPa}$ wind speed \\
ceshp8_upgl & $800 \mathrm{hPa}$ zonal velocity \\
ceshp8_vpgl & $800 \mathrm{hPa}$ meridional velocity \\
ceshp8_zpgl & $800 \mathrm{hPa}$ vorticity \\
ceshp8thpgl & $800 \mathrm{hPa}$ wind direction \\
ceshp8zhpgl & $800 \mathrm{hPa}$ divergence \\
ceshp500pgl & Relative humidity at $500 \mathrm{hPa}$ \\
ceshp850pgl & Relative humidity at $850 \mathrm{hPa}$ \\
Ceshprcppgl & Total rainfall \\
ceshs500pgl & Specific humidity at $500 \mathrm{hPa}$ \\
ceshs850pgl & Specific humidity at $850 \mathrm{hPa}$ \\
ceshshumpgl & Surface-specific humidity \\
ceshtemppgl & \\
\hline & Mean temperature at $2 \mathrm{~m} \mathrm{height}$ \\
\hline
\end{tabular}

We employed the procedure developed by Mahmood and Babel [19] to finalize the predictors used at each station. Following this approach, the correlations $r_{i}$ between the predictand and 26 predictors were computed $(i \in[1,26])$, and the one with the highest correlation $\left(r_{k}\right)$ was selected as the first predictor. Then, the partial correlations $r_{p_{j}}$ between the remaining predictors (i.e., $j \neq k$ ) and the predictand, conditioned on the presence of the previously selected predictor, were obtained. The percentage reduction in correlation (PRC) was then calculated for these remaining predictors as follows:

$$
\operatorname{PRC}_{j}=\left(\frac{r_{j}-r_{p_{j}}}{r_{j}}\right) ; \quad(1 \leq j \leq 26 ; j \neq k) .
$$

The predictor which has the minimum PRC is selected as the second predictor. Subsequent predictors were selected by repeating the above steps (i.e., computing partial correlations and selecting the one with the least PRC). The first predictor selected through the above procedure is also referred to as the super predictor (SP). Table 2 lists the super predictors (in italic) and two next predictors selected at each station. Mostly, one to three predictors are sufficient to explain the predictand without multicollinearity [19]. The correlation coefficients for super predictors were found to be $0.15,0.21,0.11$, and 0.09 for Halim, Priuk, Ciliduk, and Depok stations, respectively.
TABLE 2: List of CanESM2 predictors selected for downscaling.

\begin{tabular}{lccc}
\hline Halim & Priuk & Ciliduk & Depok \\
\hline ceshp1_vpgl & ceshp1_vpgl & ceshp1_vpgl & ceshp1_vpgl \\
ceshp1_zpgl & ceshp1zhpgl & ceshp1_upgl & ceshshumpgl \\
ceshp8thpgl & ceshplthpgl & ceshp8thpgl & ceshplthpgl \\
\hline
\end{tabular}

Once the predictors are selected, the monthly empirical relationships are derived within SDSM using the following submodels: ordinary least squares for optimization, the fourth-root transformation to account for nonnormality [12, 39], and the conditional scenario. Ordinary least square optimization method is used as it is much faster than the dual simplex method and the results are comparable [12]. The conditional scenario is suitable for dependent climate variables such as precipitation and evaporation [19]. As in LARS-WG 100 realizations of 23-year-long daily time series of rainfall are generated for all four stations for the historical (1984-2006) and future (2046-2068) time periods under scenarios RCP 4.5 and 8.5.

3.3. Description of NEX-GDDP Data. One of the main limitations of SDSM is the lack of multiple GCMs for the AR5 RCPs. To gain insights into climate model uncertainty for different RCPs, we employed the NEX-GDDP data (https://cds.nccs.nasa.gov/nex-gddp/, accessed on September $25,2016)$. This global dataset comprises $0.25^{\circ}$ resolution, bias-corrected, spatially disaggregated, and daily temperature and precipitation series from the $21 \mathrm{GCMs}$ of the Coupled Model Intercomparison Project Phase 5 (CMIP5) covering historical (1950-2005) and future (2006-2100) time periods. Details on the bias correction methodology can be found in [20], and a description of spatial disaggregation approach and the list of $21 \mathrm{GCMs}$ can be found in the technical note (https://nex.nasa.gov/nex/resources/365/, accessed on October 5, 2016). In this study, we selected 40 years of historical data, 1961-2000, to overlap the observed record and future projections, 2031-2070, to overlap the future time period of LARS-WG and SDSM. Note that 20 GCMs are used in this study because the GCM ACCESS1-0 gives unrealistic values for annual maximum daily rainfall ( $\sim 1000 \mathrm{~mm} /$ day $)$.

\section{Results and Discussion}

4.1. LARS-WG Validation. The daily mean, standard deviation, and maximum rainfall were computed for each month and each of the 100 realizations. Figure 3 shows a comparison of statistics obtained for synthetic series at each station against the observed record. In general, the statistics computed from the synthetic series agree quite well with those from observed record. The interquartile range of 100 realizations captures the statistics of the observed record for a majority of months and for all stations. The average percentage error over the months for mean and maximum daily rainfall in the generated series and the observed data is shown in Table 3. The maximum error is observed for daily maximum rainfall at Depok station (15\%). With the exception of maximum daily rainfall at Depok, the percentage error was 

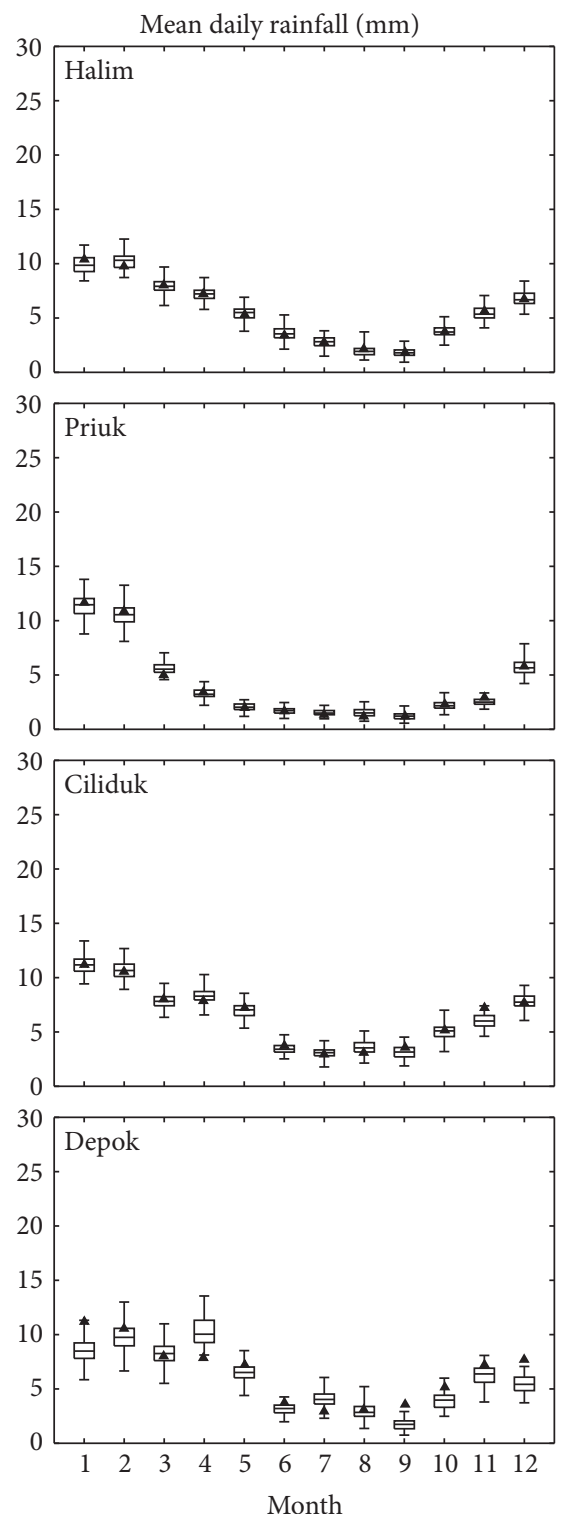

- Observed

- Generated

(a)
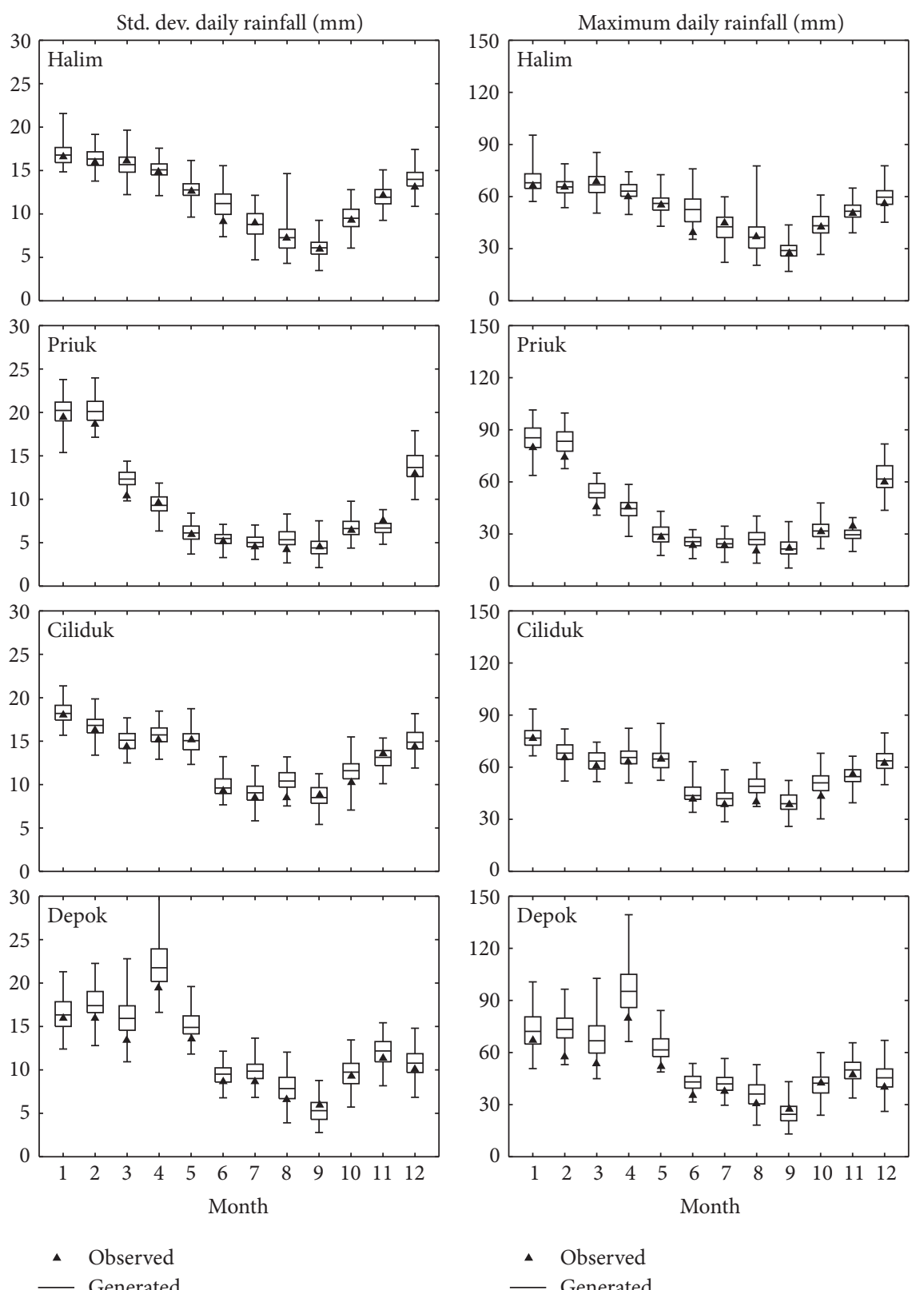

(b)

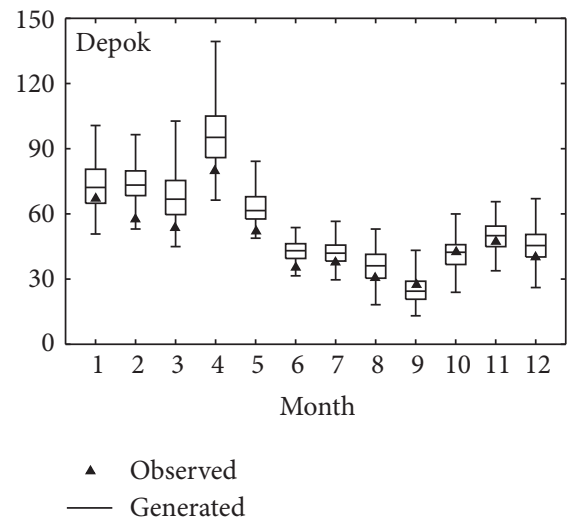

(c)

FIGURE 3: Comparison of observed mean (a), standard deviation (b), and maximum daily rainfall (c) with LARS-WG generated rainfall sequences at the four stations. The observed data are for the period of 1984-2006. The boxplots are derived from 100 independent realizations of 23-year-long LARS-WG generated data. Whiskers indicate minimum and maximum out of 100 realizations.

high during the dry months, arising from the smaller number of rainy days available for calculating the daily statistics. For example, the highest percentage error in maximum daily rainfall was found to be $33.4 \%$ in June (average rainy days of 5.3 days) and $32.9 \%$ in August (average rainy days of 3.7 days) at Halim and Priuk, respectively. Similar patterns were observed in mean and standard deviation of daily rainfall.

The annual maximum daily rainfall from the observed record was fitted with the Log Pearson Type III (LP3) probability distribution for all four stations. Figure 4 shows the probability of exceedance of empirical annual maxima along with the fitted LP3 distribution. The 95\% confidence intervals in Figure 4 were obtained using the Monte Carlo approach from Kottegoda and Rosso [40]. The empirical exceedance probabilities at all four stations lie within the $95 \%$ confidence interval illustrating that LP3 distribution is a good fit to the observed record. However, it is noted that the confidence interval is slightly larger for Depok compared to other stations. The annual maximum daily rainfall for each of the 100 realizations from synthetic series was also fitted with the LP3 probability distribution for all four stations. It is seen from Figure 5 that the RP curves from the synthetic 

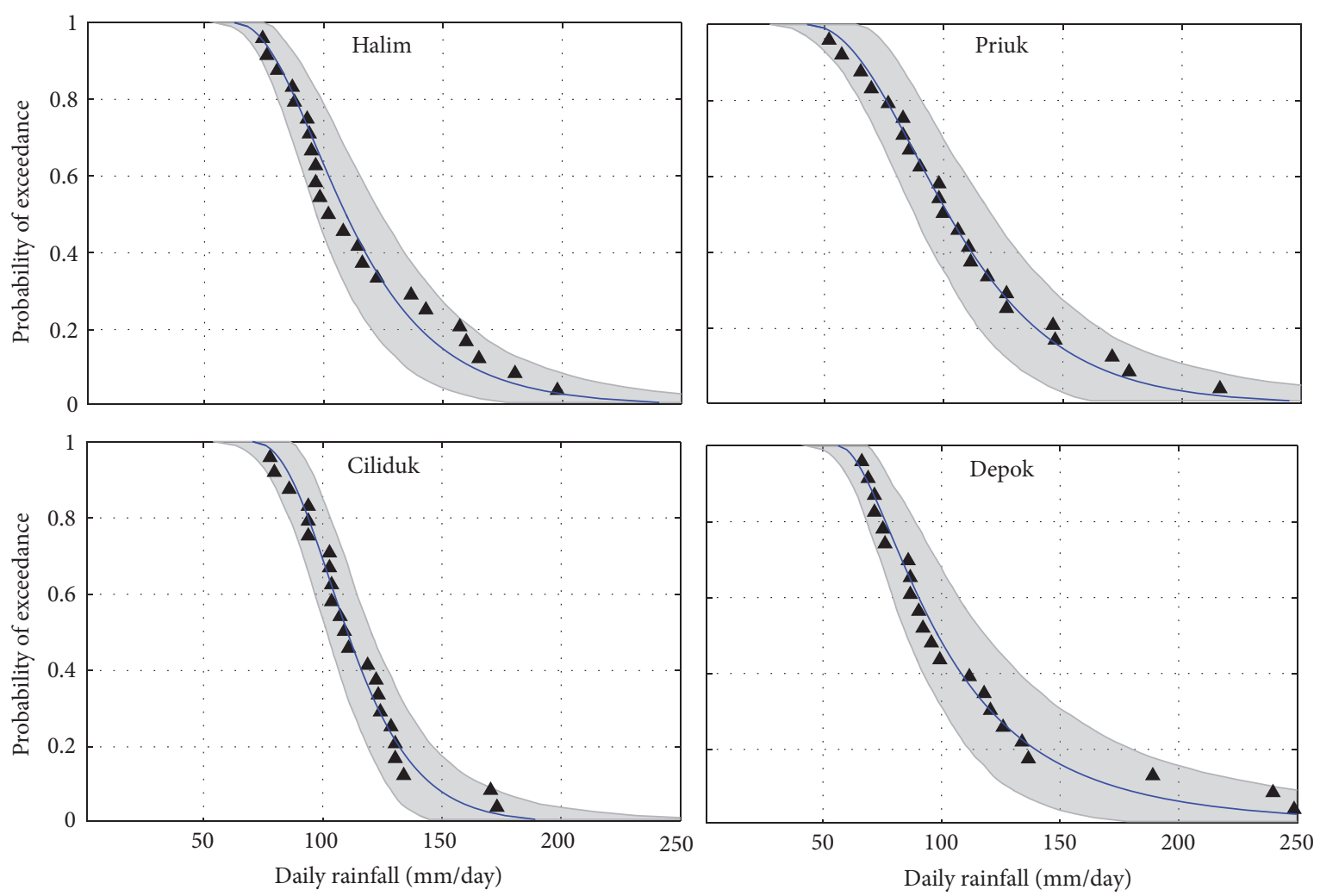

A Observed

— Fitted

$\Delta$ Observed

- Fitted

FIGURE 4: Annual maximum of daily rainfall fitted with LP3. The shaded region shows $95 \%$ confidence interval.

TABLE 3: Percentage error in daily mean and maximum rainfall averaged over 12 months.

\begin{tabular}{lcccc}
\hline \multirow{2}{*}{ Station } & \multicolumn{2}{c}{ LARS-WG } & \multicolumn{2}{c}{ SDSM } \\
& Mean & Maximum & Mean & Maximum \\
\hline Halim & 3.3 & 5.6 & 19.7 & 11.1 \\
Priuk & 7.1 & 9.4 & 15.8 & 12.7 \\
Ciliduk & 5.4 & 6.2 & 11.7 & 11.5 \\
Depok & 10.1 & 15.0 & 16.9 & 30.6 \\
\hline
\end{tabular}

series closely follow the observed RP curves except at higher return periods, where they deviate slightly. These differences at higher return periods are expected as arising from a sample size of 23 years. Larger discrepancies between RP curves of observed and synthetic annual maxima are seen for Depok, which can be attributed to higher differences between observed and synthetic daily rainfall time series at this station (Figure 3 and Table 3). In addition, Depok has larger fitting uncertainty compared to other stations (Figure 4).

The overall comparison of basic statistics (Figure 3) and RP curves (Figure 5) indicates that synthetic series generated from the LARS-WG model is satisfactory. Hereafter, these 100 realizations of LARS-WG generated synthetic data will be used as the historical values when analysing changes between historical and future daily rainfall extremes.
4.2. SDSM Validation. A comparison of daily rainfall statistics for observed and SDSM generated rainfall is shown in Figure 6. Table 3 also shows the percentage error for mean and maximum daily rainfall averaging over the months. The maximum error is observed at Depok (30.6\%) for maximum daily rainfall as LARS-WG. Similar to LARS-WG generated data, the maximum percentage error in SDSM simulations mainly occurs during dry months. The fitted daily RP curves (Figure 7) show that the RP curves at Halim and Priuk closely follow those derived from the observed record. However they deviate noticeably for Ciliduk and Depok stations. This is partly attributed to the fact that Halim and Priuk are in one CanESM2 grid while Ciliduk and Depok stations are in an adjacent grid (Figure 1). The correlation between the predictors and the predictand is higher for Halim and Priuk than for Ciliduk and Depok.

Overall, it is observed that the percentage errors are higher in the SDSM analysis compared to LARS-WG (Table 3). That LARS-WG is capable of producing historical synthetic data better than SDSM is because the former is a weather generator that produces the synthetic series based on actual observed data while the latter depends on the empirical relationships between predictors and predictand. Furthermore the CanESM2 predictors used in SDSM have a coarse resolution $\left(\sim 2.81^{\circ}\right)$ when compared to the point-level predictands. However SDSM has an advantage of generating future rainfall time series for AR5 emission scenarios. 

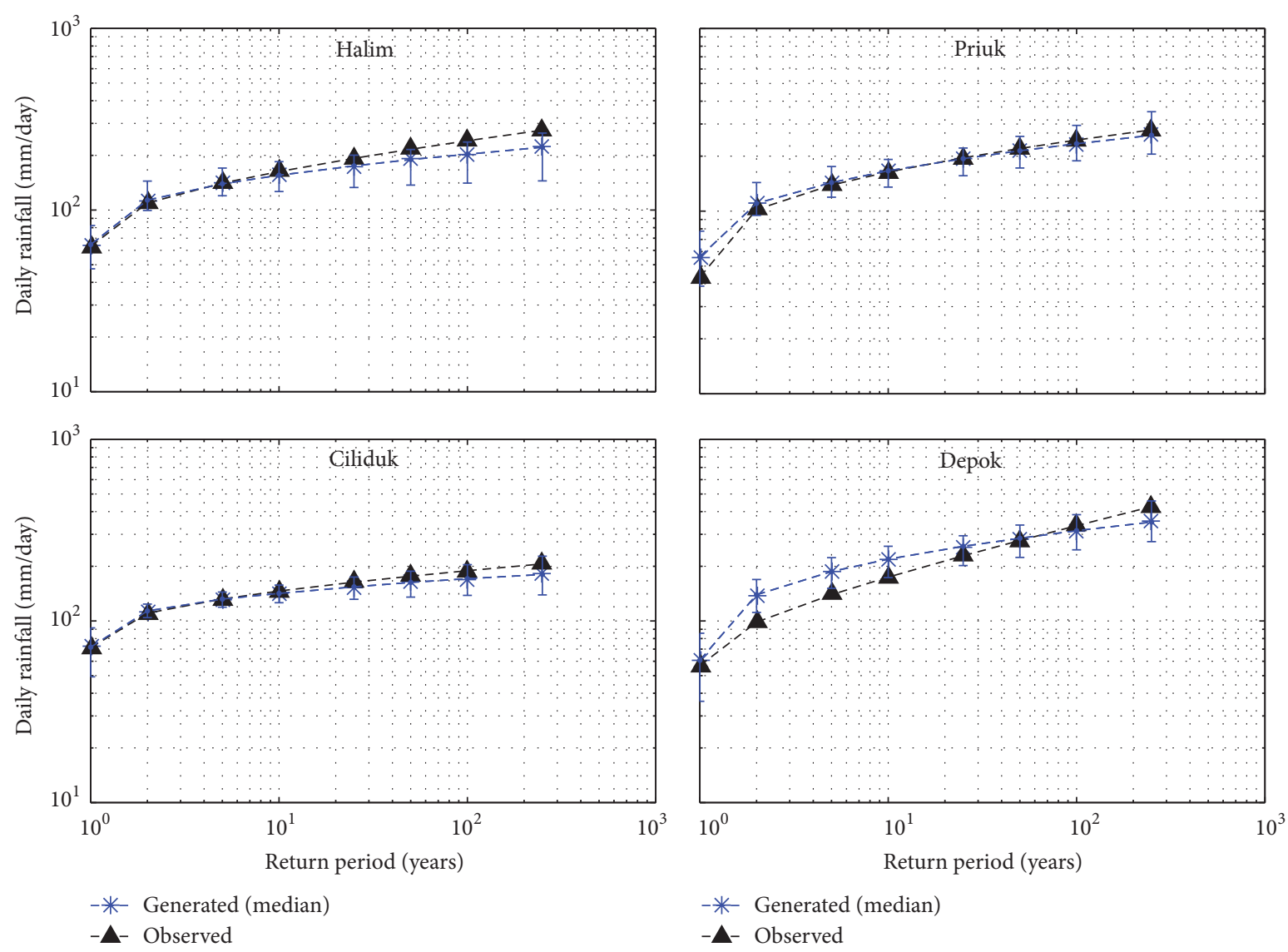

FIGURE 5: Comparison of RP curves obtained from observation with those from LARS-WG generated rainfall. Whiskers indicate minimum and maximum rainfall obtained from 100 realizations.

4.3. Future Rainfall Projections with LARS-WG. The comparison of daily RP curves between the historical and future time series for emission scenarios $\mathrm{A} 1 \mathrm{~B}$ and $\mathrm{B} 1$ is shown in Figure 8 . The medians from 100 realizations are calculated for each of 15 GCMs (shown individually as thick grey lines), and the overall median is compared with the median of the historical rainfall RP curves. Figure 8 also shows the overall GCM uncertainty (shown as shaded grey area) calculated by pooling together all 100 realizations of all 15 GCMs. All four stations experience an increase in daily rainfall at all return periods for $\mathrm{A} 1 \mathrm{~B}$ emission scenario. The stations Halim, Priuk, Ciliduk, and Depok will experience 2.4, 5.5, 6.3, and $5.7 \%$ increase in daily rainfall, respectively, at the RP of 25 years. It is evident that the climate model uncertainty has the major influence on the changes in annual maximum daily rainfall with the largest uncertainty at station Halim. The predictions with emission scenario $\mathrm{B} 1$ are lower than with $\mathrm{A} 1 \mathrm{~B}$ as expected, since the $\mathrm{A} 1 \mathrm{~B}$ scenario assumes a balanced emphasis on all energy sources while B1 assumes global solutions to meet economic, social, and environmental stability [41]. The median for the B1 emission scenario shows an increased future rainfall, though smaller than with A1B except for Halim station where a decrease is observed.

4.4. Future Rainfall Projections with SDSM. The CanESM2 predictors and the empirical relationships developed at each station using the historical time period were used to obtain daily time series for a future time period of 2046-2068 under RCP 4.5 and RCP 8.5 emission scenarios. As with the historical rainfall, 100 independent realizations of daily rainfall for the future period are generated, and the annual maximum daily rainfalls from each realization were fitted with LP3 probability distribution and the median values are calculated. Figure 9 compares the median values of historical and future daily rainfall maxima. All four stations show an increase in daily rainfall intensity under both future climate scenarios. The future daily rainfall under RCP 4.5 at 25-year RP increased by $3.2,6.0,7.3$, and $13.7 \%$ at stations Halim, Priuk, Ciliduk, and Depok, respectively. The corresponding increases are 7.0, 9.9, 3.9, and 6.4\% under the higher emission scenario RCP 8.5. Expected larger increases are seen at stations Halim and Priuk under RCP 8.5, but lower increases are seen for Ciliduk and Depok. It is noted that Ciliduk and Depok which lie on an adjacent CanESM2 grid cell had higher errors during the SDSM validation with lower correlations with the predictors (cf. Section 4.2) and this may have contributed to the predicted smaller increment.

4.5. Future Rainfall Projections with NASA-GDDP Data. The NEX-GDDP rainfall data from 20 GCMs for the historical (1961-2000) and future time period (2031-2070) are analysed. Figure 10 compares future RP curves for each GCM and 

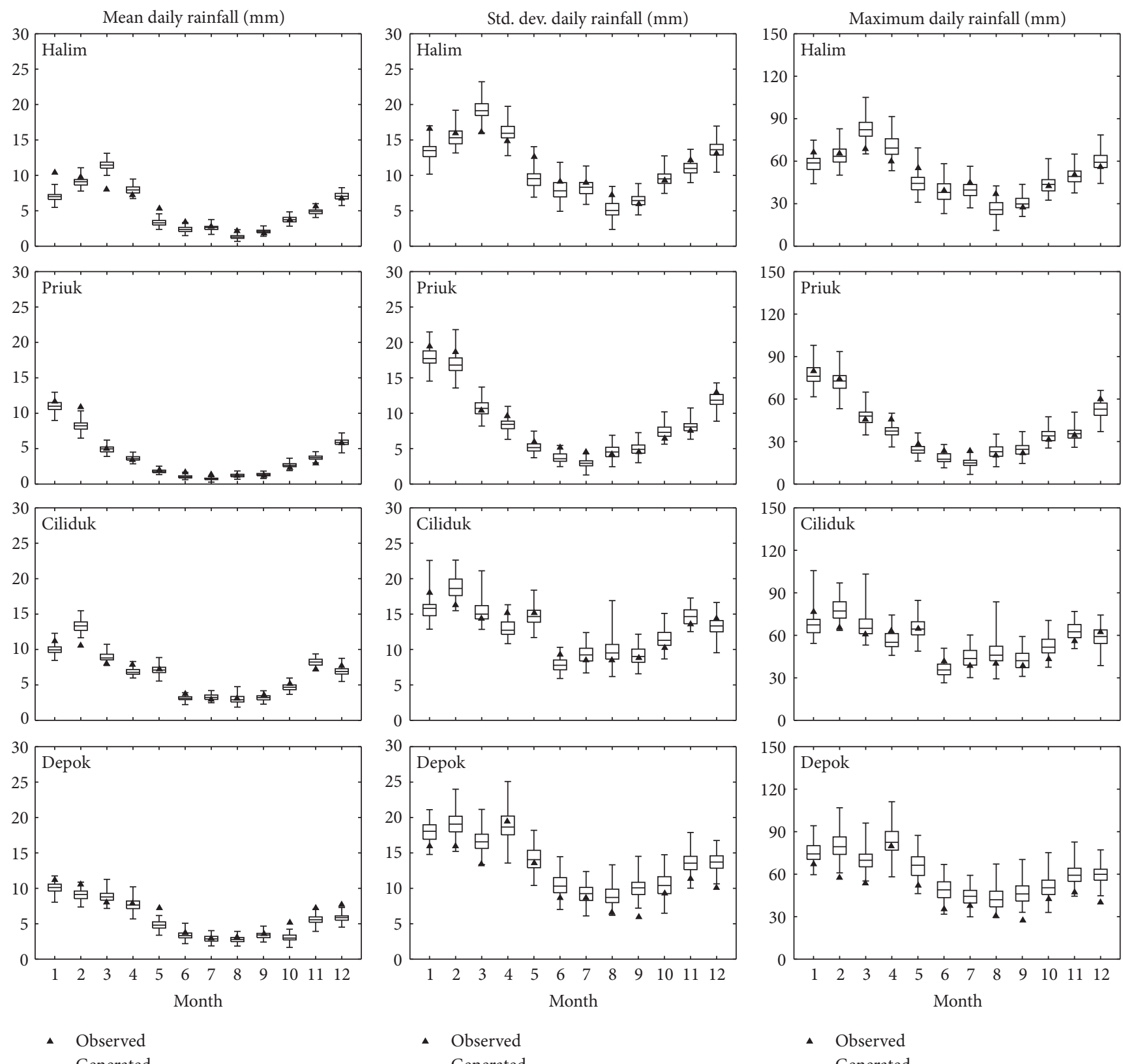

$\triangle$ Observed

- Generated

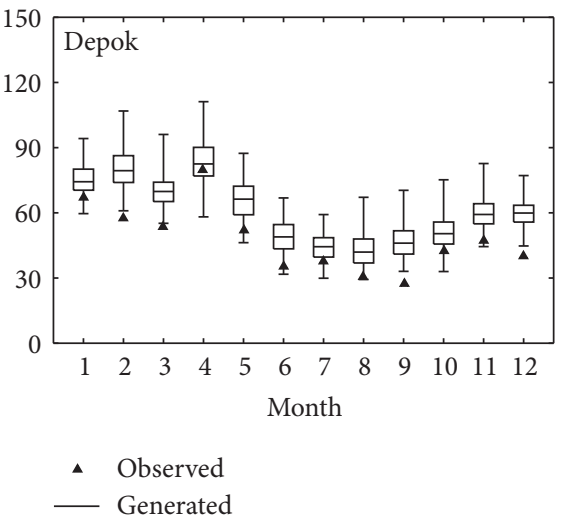

(b)

(c)

FIGURE 6: Comparison of observed mean (a), standard deviation (b), and maximum daily rainfall (c) with SDSM generated rainfall sequences at the four stations. The observed data are for the period of 1984-2006. The boxplots are obtained from 100 realizations of 23-year-long SDSM generated data. Whiskers indicate minimum and maximum out of 100 realizations.

emission scenario against the historical curves. The median of future RP curves is always higher than the corresponding historical for all stations and for both emission scenarios. For example, the RCP 4.5 emission scenario results in $10 \%, 16.5 \%$, and $12.2 \%$ increases at 25 -year return period for the three grid cells that cover the four stations. The corresponding values are $17 \%, 17.6 \%$, and $16.7 \%$ increase under RCP 8.5. Figure 10 also shows large uncertainty across the 20 different GCMs.

4.6. Comparison across Models. The results from LARS-WG (15 GCMs), SDSM (1 GCM), and NEX-GDDP (20 GCMs) future predictions are compared here. Figure 11 shows the percentage change in the future daily rainfall compared to historical for return period of 50, 100, and 250 years. The vertical bars represent 10th and 90th percentile values of the percentage change. All three approaches show an increase in future daily rainfall with one exception being from LARSWG at station Halim under emission scenario B1 which shows a decrease for all three return periods. This is attributed to AR4 B1 being an optimistic emission scenario while the other scenarios considered here are typical (A1B, RCP 4.5) or less optimistic (RCP 8.5). Hence station Halim shows an average 

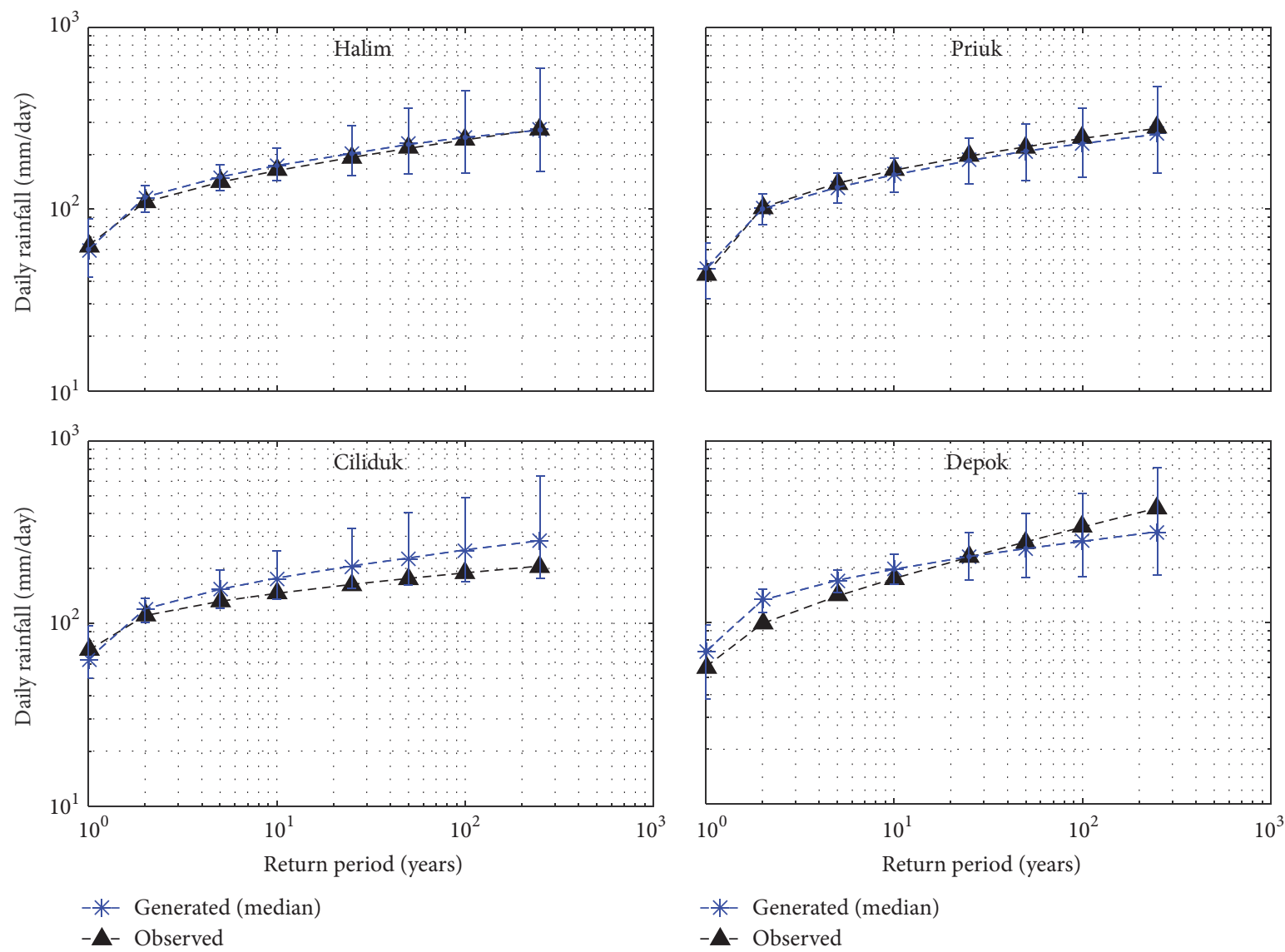

FIGURE 7: Comparison of RP curves obtained from observations with those from SDSM generated rainfall data. Whiskers indicate minimum and maximum rainfall from 100 sequences.

increase of $2.0 \%$ under LARS-WG with A1B, 2.2\% (7.5\%) under SDSM with RCP 4.5 (8.5), and 11.5\% (17.0\%) under NEX-GDDP with RCP 4.5 (8.5) in the 100-year RP daily rainfall. In general, the LARS-WG and SDSM indicate smaller changes in future rainfall compared to the NEX-GDDP. An exception to this behavior is a $20.3 \%$ increase at Depok using SDSM under RCP 4.5.

The median percentage change in rainfall between emission scenarios $\mathrm{A} 1 \mathrm{~B}$ and $\mathrm{B} 1$ ranges from 2.1 to $8.6 \%$ for the four stations. The GCM uncertainty as quantified using interpercentile range (90th-10th percentiles) is much higher, ranging from 12.5 to $42.2 \%$ and from 8.6 to $38.1 \%$ for LARS-WG A1B and B1 scenarios, respectively (Table 4). The corresponding uncertainty for NEX-GDDP is 41.7 to $60.3 \%$ and 55.5 to $62.6 \%$ for RCP 4.5 and RCP 8.5 , respectively. The uncertainty arising from the GCMs is smaller for LARSWG compared to that of NEX-GDDP (Figure 11), which is mainly due to the former's use of the change factor approach to obtain future projections. More specifically, LARS-WG derives change factors from GCM output at their native scale $\left(\sim 2.5^{\circ}\right)$ and imposes them on historical input data to obtain future rainfall projections. On the other hand, NEXGDDP data is downscaled from GCM native resolution to $25 \mathrm{~km}$. It is also noted that LARS-WG model results are with 15 GCMs under SRES scenarios, whereas NEX-GDDP data has 20 GCMs under RCP scenarios.
The above analysis was repeated for the wet (December to March) and dry (June to September) seasons. The future wet season daily rainfall is increasing for most of the cases (Figure 12). The percentage change in daily rainfall in the wet season and the corresponding GCM uncertainty are comparable to that of the annual scenario (Figures 11 and 12), except for LARS-WG result at station Halim under emission scenario B1. The similarity between wet season and annual results is expected as most of the annual daily maximum rainfall values are recorded during the wet season. For example, the percentage of annual daily maximum rainfall occurring during the wet season is $83 \%$ and $44 \%$ at Priuk and Ciliduk stations, respectively. For the dry season, the future daily rainfall shows less of a change or even a decrease (e.g., Priuk, Figure 13). Comparison of Figures 11-13 indicates that the GCM uncertainty is the largest during the dry season. Larger GCM uncertainty during the dry season is because of fewer number of rainfall days available for analysis and lower daily rainfall maxima.

The median daily rainfalls from the 100 realizations across the different models are summarized in Table 5. The annual and the wet season daily rainfall values are quite comparable and the dry season daily rainfall is much smaller with the exception of station Halim where a number of annual maximums occurred in the dry season. This is reflected in the LARS-WG simulation results where the annual projections 

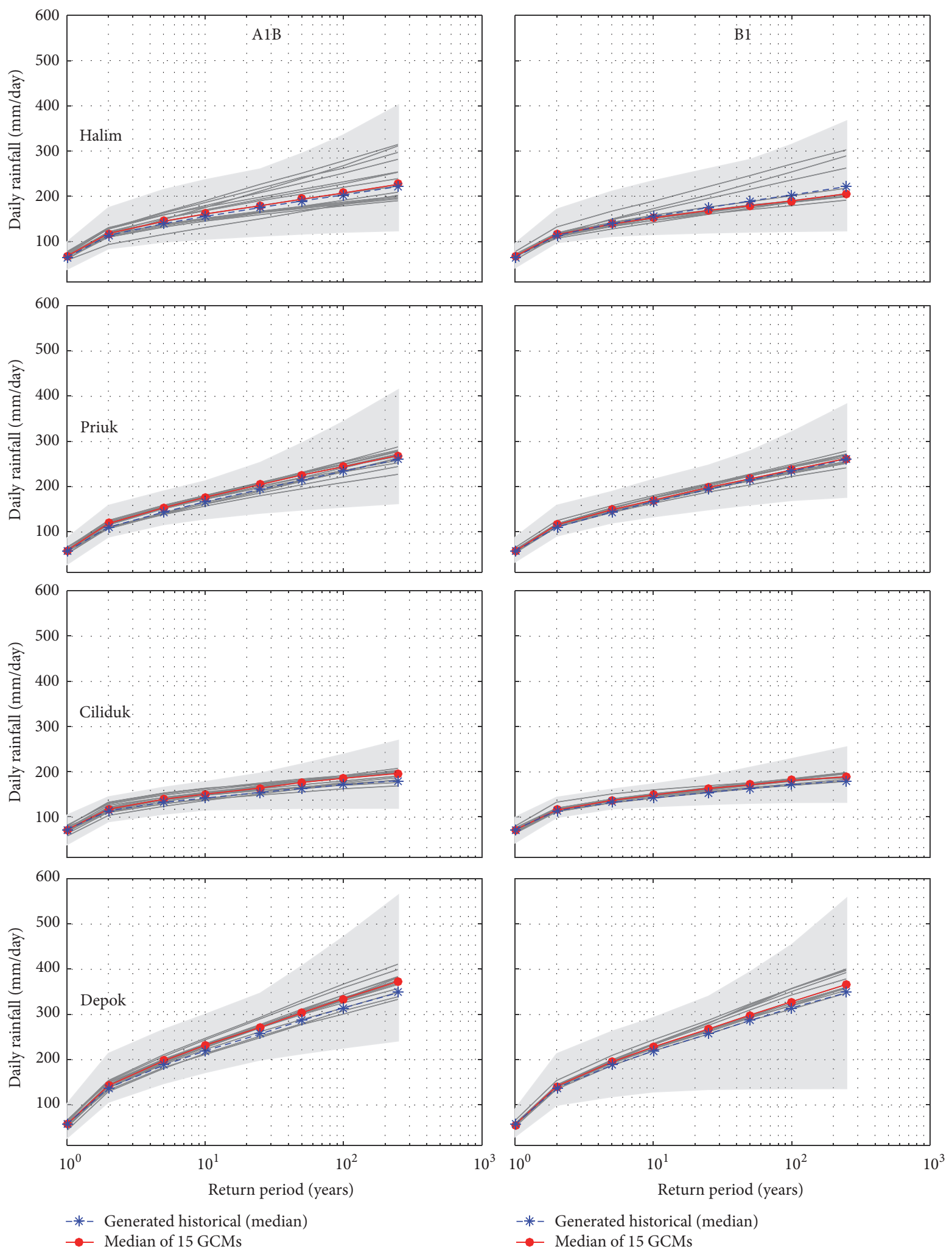

FIGURE 8: Daily RP curves comparison between GCM predictions from emission scenarios A1B and B1 for future (2046-2065) and historical generated rainfall with LARS-WG. The medians of 100 realizations for each of the 15 GCMs are indicated with thick grey line and the grey shade represents all $15 \times 100$ realizations. 

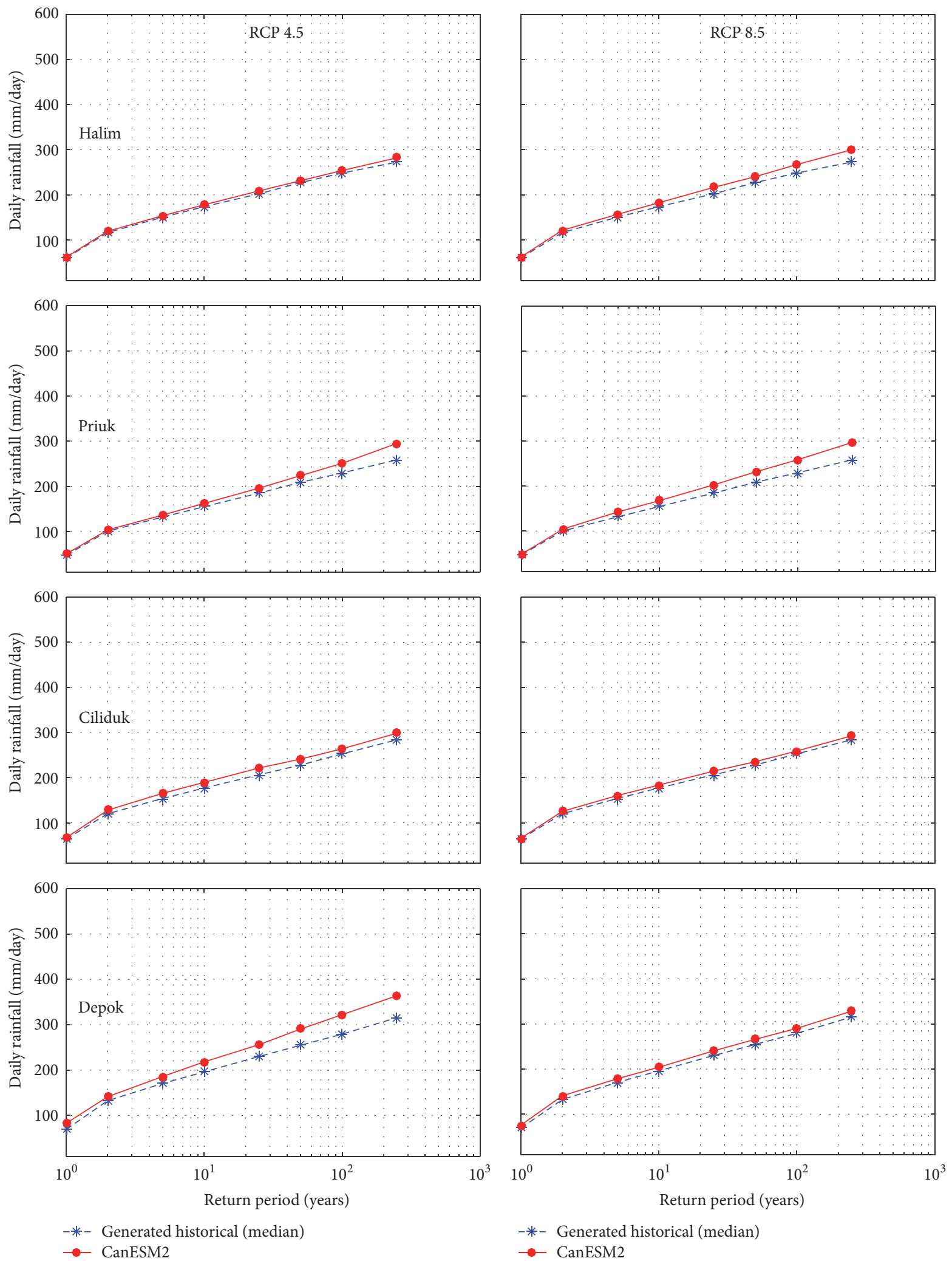

FIGURE 9: Comparison between GCM predictions for future (2046-2068) and historical generated rainfall from SDSM for ARF 5 emission scenarios RCP 4.5 and RCP 8.5. The RP curves are generated with daily annual maximum rainfall. 

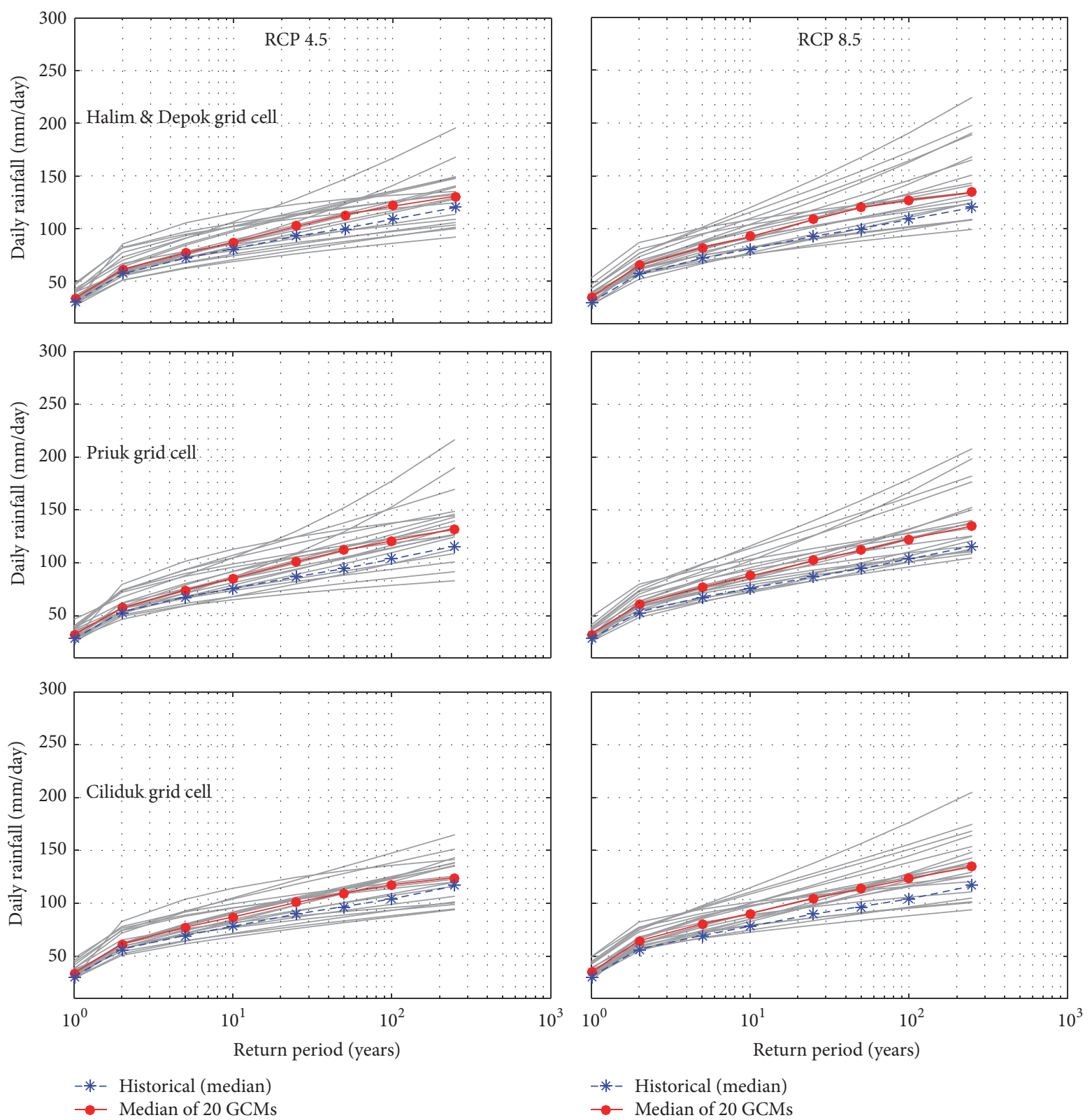

FIGURE 10: Comparison of median historical and median future predictions with $20 \mathrm{GCMs}$ and RCP 4.5 and 8.5 in $0.25^{\circ} \times 0.25^{\circ}$ grid cells. The 20 GCM predictions are indicated with thick grey lines. Stations Halim and Depok lie in a single grid cell.

TABLE 4: Comparison of median (50th) and interpercentile range (10th to 90th) of percentage changes in 100-year RP daily rainfall for LARSWG and NEX-GDDP.

\begin{tabular}{|c|c|c|c|c|c|c|c|c|}
\hline \multirow{3}{*}{ Station } & \multicolumn{4}{|c|}{ LARS-WG (AR4) } & \multicolumn{4}{|c|}{ NEX-GDDP (AR5) } \\
\hline & \multicolumn{2}{|r|}{$\mathrm{A} 1 \mathrm{~B}$} & \multicolumn{2}{|r|}{$\mathrm{B} 1$} & \multicolumn{2}{|r|}{ RCP 4.5} & \multicolumn{2}{|r|}{ RCP 8.5} \\
\hline & 50 th & 10th-90th range & 50th & 10th-90th range & 50 th & 10th-90th range & 50 th & 10th-90th range \\
\hline Halim & 2.2 & 42.2 & -6.4 & 38.1 & 11.5 & 41.7 & 17.0 & 62.6 \\
\hline Priuk & 4.2 & 13.8 & 1.2 & 8.8 & 16.7 & 60.3 & 18.5 & 61.5 \\
\hline Ciliduk & 8.4 & 12.5 & 5.6 & 8.6 & 13.0 & 44.4 & 18.2 & 55.5 \\
\hline Depok & 6.5 & 16.2 & 4.4 & 13.2 & 11.5 & 41.7 & 17.0 & 62.6 \\
\hline
\end{tabular}


TABLE 5: Daily rainfall from annual and seasonal analysis for historical and future time periods.

\begin{tabular}{|c|c|c|c|c|c|c|c|c|}
\hline \multirow[t]{2}{*}{ Station } & \multirow[t]{2}{*}{ Return period } & \multirow[t]{2}{*}{ Model } & \multicolumn{3}{|c|}{ Historical } & \multicolumn{3}{|c|}{$\begin{array}{l}\text { Future-A1B for LARS-WG/RCP4.5 for } \\
\text { NEX-GDDP }\end{array}$} \\
\hline & & & Annual & Wet & Dry & Annual & Wet & Dry \\
\hline \multirow{9}{*}{ Halim } & \multirow{3}{*}{50} & LARS-WG & 189.7 & 164.0 & 209.8 & 193.6 & 177.2 & 212.2 \\
\hline & & SDSM & 227.1 & 206.5 & 156.6 & 231.4 & 208.2 & 159.7 \\
\hline & & NEX-GDDP & 100.2 & 101.0 & 51.9 & 113.1 & 113.5 & 49.1 \\
\hline & \multirow{3}{*}{100} & LARS-WG & 202.9 & 176.1 & 239.3 & 207.3 & 191.7 & 241.3 \\
\hline & & SDSM & 248.3 & 230.3 & 179.9 & 253.9 & 228.2 & 182.0 \\
\hline & & NEX-GDDP & 108.7 & 109.7 & 56.4 & 121.2 & 123.0 & 52.2 \\
\hline & \multirow{3}{*}{250} & LARS-WG & 221.8 & 190.8 & 278.6 & 226.6 & 209.1 & 280.7 \\
\hline & & SDSM & 272.6 & 260.3 & 207.7 & 282.1 & 259.3 & 213.5 \\
\hline & & NEX-GDDP & 120.0 & 119.8 & 59.6 & 130.7 & 131.5 & 57.1 \\
\hline \multirow{9}{*}{ Priuk } & \multirow{3}{*}{50} & LARS-WG & 214.1 & 215.9 & 88.3 & 225.3 & 225.6 & 82.5 \\
\hline & & SDSM & 208.7 & 208.1 & 112.7 & 223.5 & 220.7 & 101.7 \\
\hline & & NEX-GDDP & 94.5 & 96.4 & 39.2 & 111.8 & 112.1 & 39.3 \\
\hline & \multirow{3}{*}{100} & LARS-WG & 233.9 & 238.0 & 91.6 & 243.8 & 244.9 & 86.4 \\
\hline & & SDSM & 229.6 & 231.4 & 132.4 & 250.8 & 251.7 & 115.2 \\
\hline & & NEX-GDDP & 103.5 & 106.1 & 43.9 & 120.8 & 121.4 & 42.1 \\
\hline & \multirow{3}{*}{250} & LARS-WG & 260.2 & 261.3 & 95.5 & 268.9 & 273.1 & 90.0 \\
\hline & & SDSM & 258.7 & 262.7 & 159.1 & 295.0 & 295.8 & 133.5 \\
\hline & & NEX-GDDP & 115.9 & 119.6 & 47.8 & 132.3 & 132.3 & 45.7 \\
\hline \multirow{9}{*}{ Ciliduk } & \multirow{3}{*}{50} & LARS-WG & 163.0 & 168.5 & 133.9 & 176.2 & 178.5 & 132.9 \\
\hline & & SDSM & 228.0 & 203.4 & 178.3 & 241.2 & 225.5 & 174.8 \\
\hline & & NEX-GDDP & 96.9 & 97.0 & 55.5 & 109.7 & 111.0 & 53.2 \\
\hline & \multirow{3}{*}{100} & LARS-WG & 170.9 & 181.4 & 140.5 & 185.3 & 191.3 & 138.6 \\
\hline & & SDSM & 252.7 & 224.1 & 199.5 & 264.0 & 249.6 & 197.0 \\
\hline & & NEX-GDDP & 104.1 & 103.3 & 58.6 & 117.6 & 118.6 & 56.8 \\
\hline & \multirow{3}{*}{250} & LARS-WG & 180.3 & 197.9 & 147.9 & 196.1 & 207.4 & 147.5 \\
\hline & & SDSM & 284.0 & 254.2 & 230.0 & 298.6 & 281.2 & 227.5 \\
\hline & & NEX-GDDP & 116.4 & 114.4 & 62.7 & 124.3 & 125.8 & 62.6 \\
\hline \multirow{9}{*}{ Depok } & \multirow{3}{*}{50} & LARS-WG & 286.4 & 269.3 & 119.3 & 303.3 & 286.7 & 118.6 \\
\hline & & SDSM & 254.7 & 207.9 & 184.4 & 295.7 & 220.7 & 200.3 \\
\hline & & NEX-GDDP & 100.2 & 101.0 & 51.9 & 113.1 & 113.5 & 49.1 \\
\hline & \multirow{3}{*}{100} & LARS-WG & 314.0 & 303.8 & 125.6 & 334.3 & 322.1 & 124.8 \\
\hline & & SDSM & 279.2 & 230.0 & 206.5 & 336.0 & 245.3 & 230.9 \\
\hline & & NEX-GDDP & 108.7 & 109.7 & 56.4 & 121.2 & 123.0 & 52.2 \\
\hline & \multirow{3}{*}{250} & LARS-WG & 347.9 & 343.3 & 137.0 & 373.0 & 364.5 & 134.2 \\
\hline & & SDSM & 315.5 & 254.4 & 244.9 & 388.9 & 279.0 & 275.3 \\
\hline & & NEX-GDDP & 120.0 & 119.8 & 59.6 & 130.7 & 131.5 & 57.1 \\
\hline
\end{tabular}

are consistent with the dry season where other stations are consistent with wet season (Figures 11, 12, and 13). The annual maximum daily rainfall shows an average increase as high as $20 \%$ in the 100 -year return period in the future. According to [42], the current average 100-year RP rainfall of $252 \mathrm{~mm}$ /day results in a discharge of 1103 and $824 \mathrm{~m}^{3} / \mathrm{s}$ for Ciliwung and Cengkareng rivers, two of the three main rivers of Jakarta, respectively, and leads to a direct economic loss of USD397 million in the flood plain surrounded by these rivers. In addition, an increase in the future 100 -year RP rainfall by $20 \%$ will have a corresponding increase in flood discharge of $28 \%$, which leads to $42 \%$ increase in direct economic loss.

\section{Conclusions}

We assessed the impact of changing climate on local-scale annual and seasonal maximum daily rainfall using different downscaling models. The future daily rainfall was generated with LARS-WG and SDSM at four stations in Jakarta, and the RP curves were compared against the observed. While 


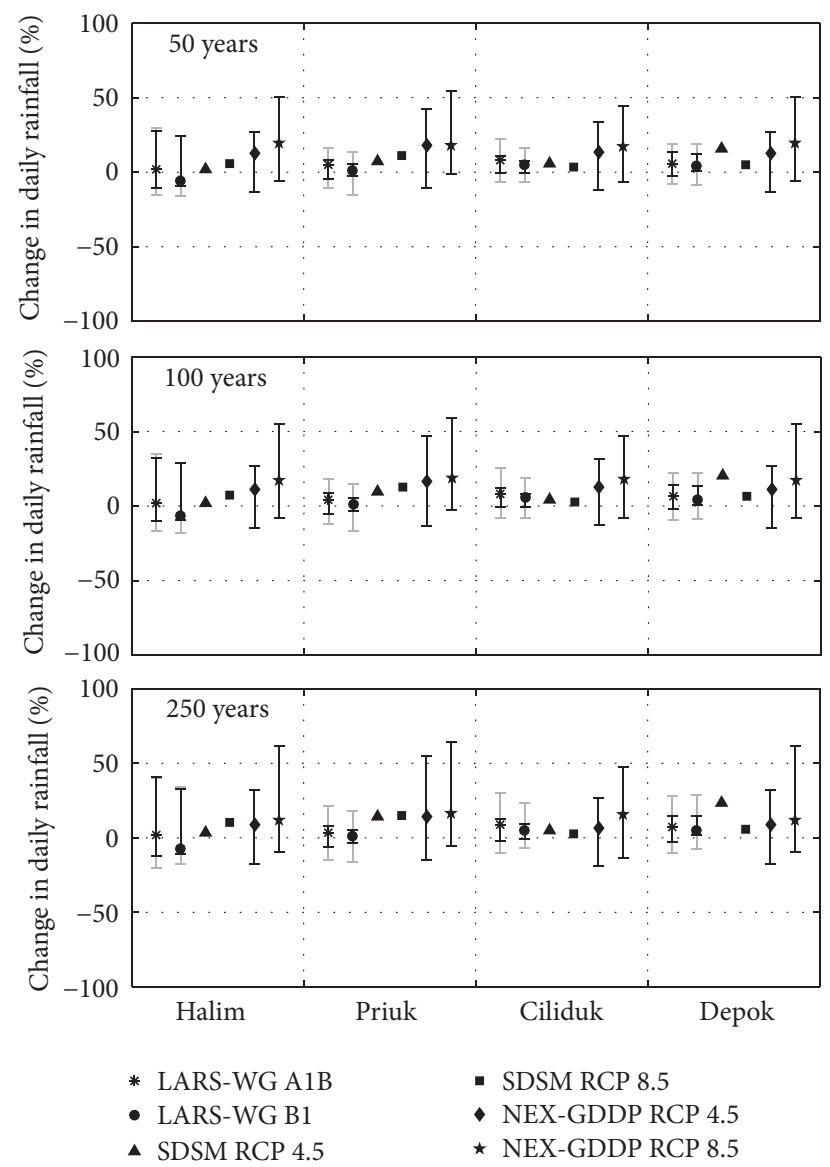

FIGURE 11: Comparison of percentage change in the annual maximum daily rainfall for future time period using LARS-WG (20462065), SDSM (2046-2068), and NEX-GDDP (2041-2070) with different emission scenarios. Dark vertical bars denote 10th and 90th percentile values for all GCMs which for LARS-WG is for the medians from 100 realizations for each of the GCMs. The light vertical bars for LARS-WG denote 10th and 90th percentiles obtained by pooling 100 realizations across all GCMs.

15 GCMs were used for LARS-WG analysis under AR4 SRES $\mathrm{A} 1 \mathrm{~B}$ and $\mathrm{B} 1$ emission scenarios, only one GCM under AR5 RCP 4.5 and 8.5 scenarios was available and used in the SDSM simulations. 20 GCMs were used from the gridded NEXGDDP data also under RCP 4.5 and 8.5.

The projections with all three approaches show that the daily rainfall maximum increases in the Jakarta region with consequent implications for future flood potential. Uncertainty from GCMs is seen to be much higher than uncertainty from emission scenarios. Future seasonal daily rainfall maximum increases for the wet season but the dry season did not exhibit a consistent increase or decrease across the models. GCM uncertainty is also higher in the dry season. The changes in wet season daily rainfall maximum exhibit similar behavior as the annual scenario as the latter is mainly controlled by the wet season for this study region. The study showed that the average increase in 100-year RP rainfall can be as high as $20 \%$ in the future. According to loss curves from [42] for the same study region, this can lead
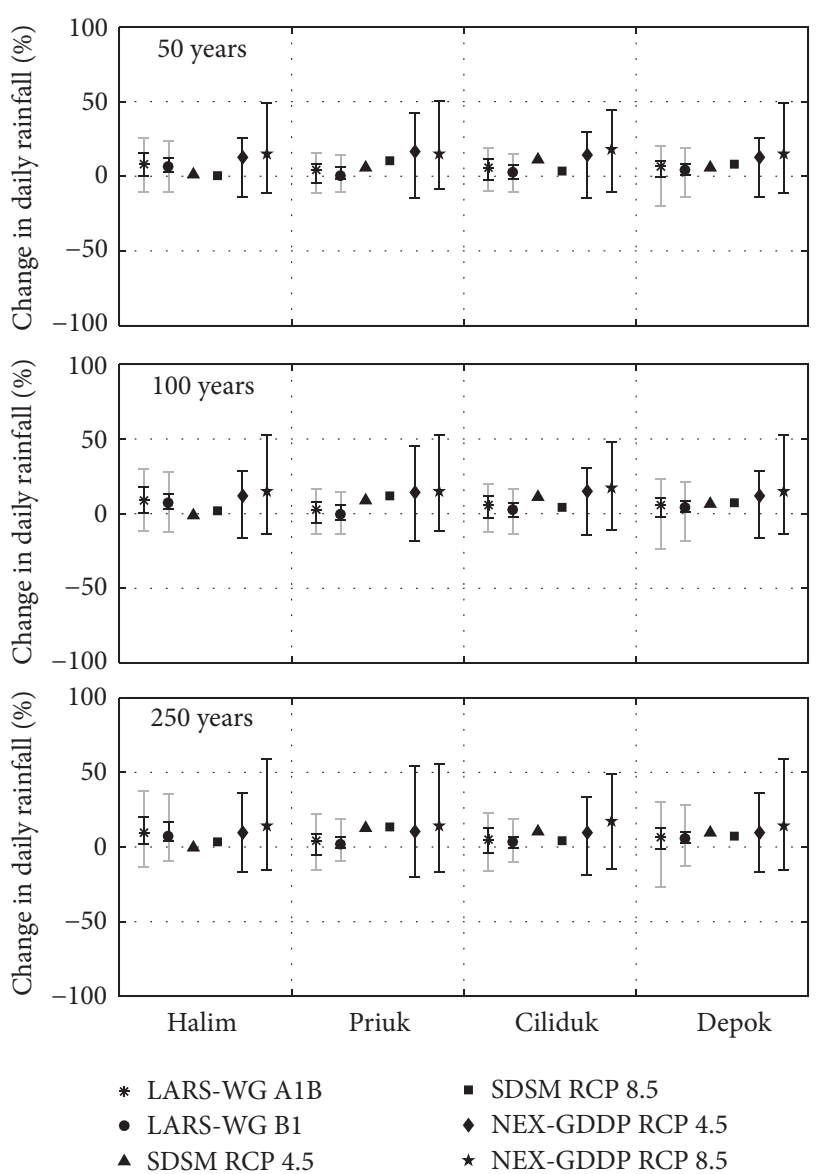

FIGURE 12: Same as Figure 11 but for wet season (December to March).

to a significant increase in flood discharge $(28 \%)$ and direct economic damage (42\%).

The study showed that the uncertainties arising from the use of different GCMs are predominant compared to those arising from different statistical downscaling approaches and emission scenarios. Given the large GCM uncertainty, deterministic (e.g., from ensemble averaging) and probabilistic (e.g., specific percentile ranges) rainfall estimates can be propagated through the hydrologic modelling chain to assess the impact of climate change on future flooding. The analysis reported here facilitates decision regarding interpretation of model results across different spatial scales and emission scenarios. It helps emergency management authorities in better decision making regarding future mitigation options for a flood-vulnerable city like Jakarta. However, further research is needed to reduce the GCM uncertainty in order to facilitate policy-makers to draw more robust future flood mitigation plans. While this study examined local-scale changes in the seasonal and annual maximum daily rainfall in Jakarta, the results are broadly applicable to other nearequatorial regions in Southeast Asia due to similarities in climatology. Extensions on the reported work can be achieved with an updated LARS-WG containing newer AR5 RCP emission scenarios, updated SDSM with a larger number of GCMs, and finer resolution gridded data. 


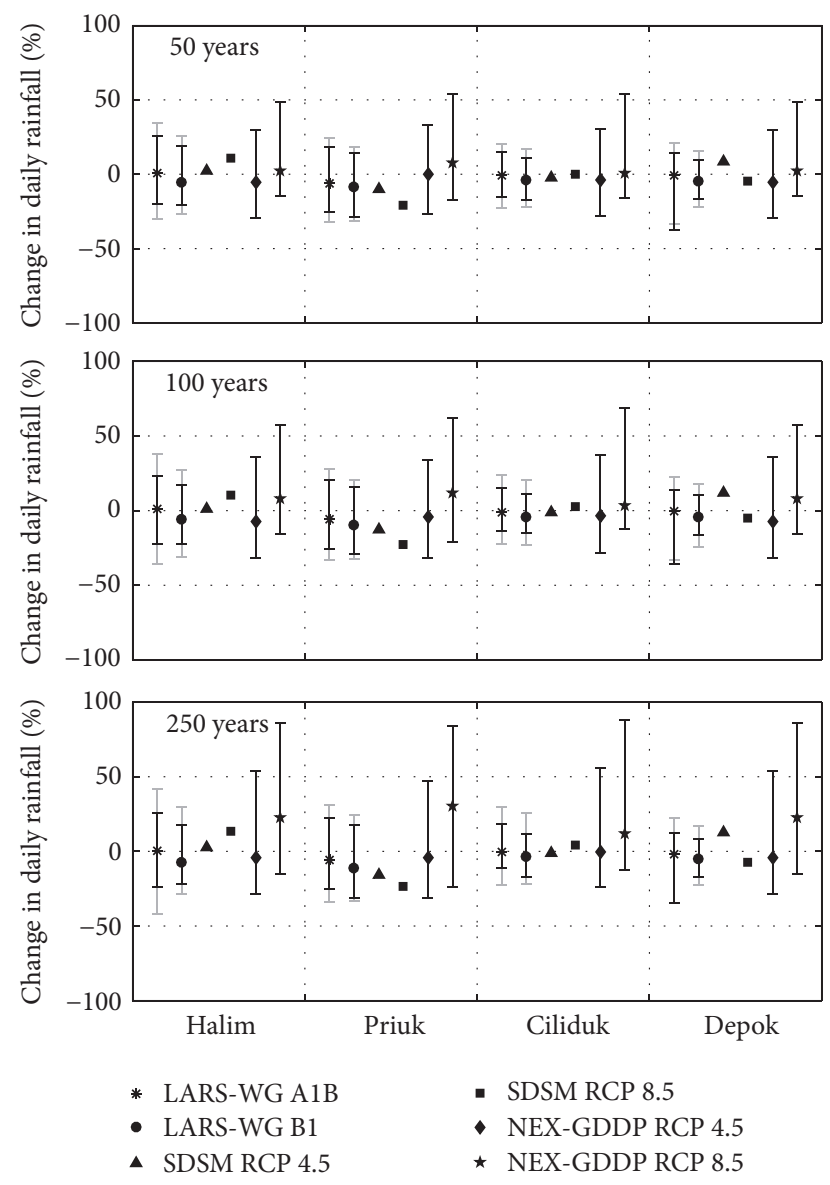

FIGURE 13: Same as Figure 11 but for dry season (June to September).

\section{Competing Interests}

The authors declare that there is no conflict of interests regarding the publication of this paper.

\section{Acknowledgments}

This research received funding from the Singapore Ministry of Education Tier II Program, NTU's Nanyang Environment and Water Research Institute, and the Future Resilient Systems program is gratefully acknowledged. The LARS-WG used here was developed by M.A. Semenov and E.M. Barrow distributed by Rothamsted Research. SDSM downscaling package is distributed by Professor Wilby and Dr. Dawson, on behalf of the UK Environment Agency. Climate scenarios used were from the NEX-GDDP dataset, prepared by the Climate Analytics Group and NASA Ames Research Center using the NASA Earth Exchange, and distributed by the NASA Center for Climate Simulation (NCCS).

\section{References}

[1] IPCC, Intergovernmental Panel on Climate Change 2007: Synthesis Report, IPCC, 2007.
[2] IPCC, Intergovernmental Panel on Climate Change 2014: Synthesis Report, IPCC, 2014.

[3] D. Coumou and S. Rahmstorf, "A decade of weather extremes," Nature Climate Change, vol. 2, no. 7, pp. 491-496, 2012.

[4] I. M. Held and B. J. Soden, "Robust responses of the hydrological cycle to global warming," Journal of Climate, vol. 19, no. 21, pp. 5686-5699, 2006.

[5] S.-K. Min, X. Zhang, F. W. Zwiers, and G. C. Hegerl, "Human contribution to more-intense precipitation extremes," Nature, vol. 470, no. 7334, pp. 378-381, 2011.

[6] M. L. Roderick, F. Sun, W. H. Lim, and G. D. Farquhar, "A general framework for understanding the response of the water cycle to global warming over land and ocean," Hydrology and Earth System Sciences, vol. 18, no. 5, pp. 1575-1589, 2014.

[7] R. Chadwick, P. Good, G. Martin, and D. P. Rowell, "Large rainfall changes consistently projected over substantial areas of tropical land," Nature Climate Change, vol. 6, no. 2, pp. 177-181, 2016.

[8] C. Liu and R. P. Allan, "Observed and simulated precipitation responses in wet and dry regions 1850-2100," Environmental Research Letters, vol. 8, no. 3, Article ID 034002, 2013.

[9] M. G. Donat, A. L. Lowry, L. V. Alexander, P. A. O’Gorman, and N. Maher, "More extreme precipitation in the world's dry and wet regions," Nature Climate Change, vol. 6, no. 5, pp. 508-513, 2016.

[10] G. C. Hegerl, E. Black, R. P. Allan et al., "Challenges in quantifying changes in the global water cycle," Bulletin of the American Meteorological Society, vol. 96, no. 7, pp. 1097-1115, 2015.

[11] A. S. Pepler, L. V. Alexander, J. P. Evans, and S. C. Sherwood, "Zonal winds and southeast Australian rainfall in global and regional climate models," Climate Dynamics, vol. 46, no. 1-2, pp. 123-133, 2016.

[12] J. Huang, J. Zhang, Z. Zhang, C. Xu, B. Wang, and J. Yao, "Estimation of future precipitation change in the Yangtze River basin by using statistical downscaling method," Stochastic Environmental Research \& Risk Assessment, vol. 25, no. 6, pp. 781-792, 2011.

[13] R. L. Wilby, H. Hassan, and K. Hanaki, "Statistical downscaling of hydrometeorological variables using general circulation model output," Journal of Hydrology, vol. 205, no. 1-2, pp. 1-19, 1998.

[14] H. J. Fowler, S. Blenkinsop, and C. Tebaldi, "Linking climate change modelling to impacts studies: recent advances in downscaling techniques for hydrological modelling," International Journal of Climatology, vol. 27, no. 12, pp. 1547-1578, 2007.

[15] D. E. Rupp, S. Li, P. W. Mote et al., "Seasonal spatial patterns of projected anthropogenic warming in complex terrain: a modeling study of the western US," Climate Dynamics, pp. 1-23, 2016.

[16] B. S. Kim, H. S. Kim, B. H. Seoh, and N. W. Kim, "Impact of climate change on water resources in Yongdam Dam Basin, Korea," Stochastic Environmental Research and Risk Assessment, vol. 21, no. 4, pp. 355-373, 2007.

[17] R. L. Wilby, C. W. Dawson, and E. M. Barrow, "SDSM-a decision support tool for the assessment of regional climate change impacts," Environmental Modelling and Software, vol. 17, no. 2, pp. 145-157, 2002.

[18] M. Z. Hashmi, A. Y. Shamseldin, and B. W. Melville, "Comparison of SDSM and LARS-WG for simulation and downscaling of extreme precipitation events in a watershed," Stochastic 
Environmental Research and Risk Assessment, vol. 25, no. 4, pp. 475-484, 2011.

[19] R. Mahmood and M. S. Babel, "Evaluation of SDSM developed by annual and monthly sub-models for downscaling temperature and precipitation in the Jhelum basin, Pakistan and India," Theoretical and Applied Climatology, vol. 113, no. 1-2, pp. 27-44, 2013.

[20] B. Thrasher, E. P. Maurer, C. McKellar, and P. B. Duffy, "Technical Note: bias correcting climate model simulated daily temperature extremes with quantile mapping," Hydrology and Earth System Sciences, vol. 16, no. 9, pp. 3309-3314, 2012.

[21] A. Ahmadalipour, H. Moradkhani, and M. Svoboda, "Centennial drought outlook over the CONUS using NASA-NEX downscaled climate ensemble," International Journal of Climatology, 2016.

[22] T. Firman, I. M. Surbakti, I. C. Idroes, and H. A. Simarmata, "Potential climate-change related vulnerabilities in Jakarta: challenges and current status," Habitat International, vol. 35, no. 2, pp. 372-378, 2011.

[23] Y. Budiyono, J. C. J. H. Aerts, D. Tollenaar, and P. J. Ward, "River flood risk in Jakarta under scenarios of future change," Natural Hazards and Earth System Sciences, vol. 16, no. 3, pp. 757-774, 2016.

[24] S. Sagala, J. Lassa, H. Yasaditama, and D. Hudalah, The Evolution of Risk and Vulnerability in Greater Jakarta: Contesting Government Policy in Dealing with a Megacity's Exposure to Flooding: An Academic Response to Jakarta Floods in January 2013, Institute of Resource Governance and Social Change (IRGSC), 2013.

[25] BPS-Indonesia, Statistical Yearbook of Indonesia, Badan Pusat Statistik (BPS) Indonesia, Jakarta, Indonesia, 2015.

[26] T. W. Hadi, T. Horinouchi, T. Tsuda, H. Hashiguchi, and S. Fukao, "Sea-breeze circulation over Jakarta, Indonesia: a climatology based on boundary layer radar observations," Monthly Weather Review, vol. 130, no. 9, pp. 2153-2166, 2002.

[27] P. J. Ward, M. A. Marfai, F. Yulianto, D. R. Hizbaron, and J. C. J. H. Aerts, "Coastal inundation and damage exposure estimation: a case study for Jakarta," Natural Hazards, vol. 56, no. 3, pp. 899916, 2011.

[28] J. Liu, C. D. Doan, S. Liong, R. Sanders, A. T. Dao, and T. Fewtrell, "Regional frequency analysis of extreme rainfall events in Jakarta," Natural Hazards, vol. 75, no. 2, pp. 1075-1104, 2015.

[29] N. J. Trilaksono, S. Otsuka, S. Yoden, K. Saito, and S. Hayashi, "Dependence of model-simulated heavy rainfall on the horizontal resolution during the Jakarta Flood event in JanuaryFebruary 2007," SOLA-Scientific Online Letters on the Atmosphere, vol. 7, pp. 193-196, 2011.

[30] P. V. Mandapaka, V. Daksiya, X. Qin, and E. Y. M. Lo, "Assessing the effect of changing climate on daily rainfall extremes in Jakarta-a weather generator approach," in Proceedings of the World Engineers Summit on Climate Change (WES '15), Singapore, 2015.

[31] P. Racsko, L. Szeidl, and M. Semenov, "A serial approach to local stochastic weather models," Ecological Modelling, vol. 57, no. 1-2, pp. 27-41, 1991.

[32] M. A. Semenov and E. M. Barrow, "Use of a stochastic weather generator in the development of climate change scenarios," Climatic Change, vol. 35, no. 4, pp. 397-414, 1997.

[33] M. A. Semenov and P. Stratonovitch, "Adapting wheat ideotypes for climate change: accounting for uncertainties in CMIP5 climate projections," Climate Research, vol. 65, pp. 123-139, 2015.
[34] M. A. Semenov and P. Stratonovitch, "Use of multi-model ensembles from global climate models for assessment of climate change impacts," Climate Research, vol. 41, no. 1, pp. 1-14, 2010.

[35] X. S. Qin and Y. Lu, "Study of climate change impact on flood frequencies: a combined weather generator and hydrological modeling approach," Journal of Hydrometeorology, vol. 15, no. 3, pp. 1205-1219, 2014.

[36] C. Ma, S. Pan, G. Wang, Y. Liao, and Y.-P. Xu, "Changes in precipitation and temperature in Xiangjiang River Basin, China," Theoretical and Applied Climatology, vol. 123, no. 3-4, pp. 859-871, 2016.

[37] DPU, Daily Rainfall, Dinas Pekerjaan Umum-Public Works Department via P.T. Multimera Harapan, Jakarta, Indonesia, 2009.

[38] M. A. Semenov and E. M. Barrow, "LARS-WG: a stochastic weather generator for use in climate impact studies," in Version 3.0 User Manual, 2002.

[39] M. S. Khan, P. Coulibaly, and Y. Dibike, "Uncertainty analysis of statistical downscaling methods," Journal of Hydrology, vol. 319, no. 1-4, pp. 357-382, 2006.

[40] N. T. Kottegoda and R. Rosso, Statistics, Probability, and Reliability for Civil and Environmental Engineers, McGraw-Hill, New York, NY, USA, 1997.

[41] IPCC, Intergovernmental Panel on Climate Change Special Report: Emission Scenario, 2000.

[42] V. Daksiya, H. T. Su, E. Y. Lo, and S. H. Cheung, "Analyzing uncertain rainfall in flood mitigation using MCDA," in Proceedings of the Symposium on Reliability of Engineering Systems, pp. 295-304, Taipei, Taiwan, October 2015. 

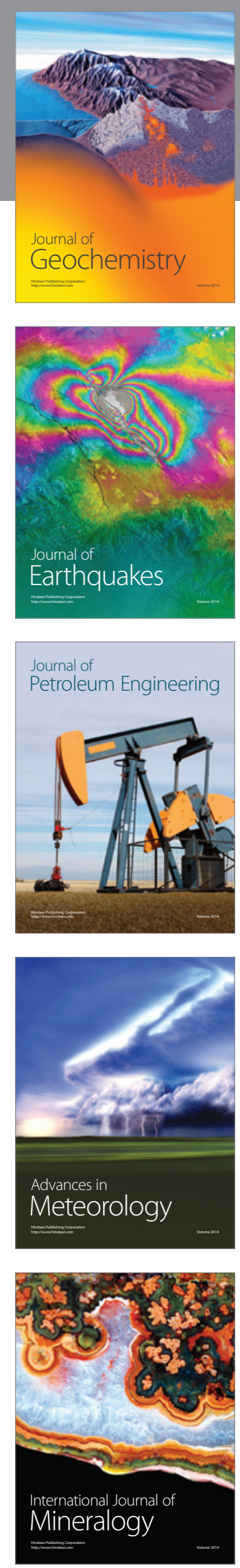
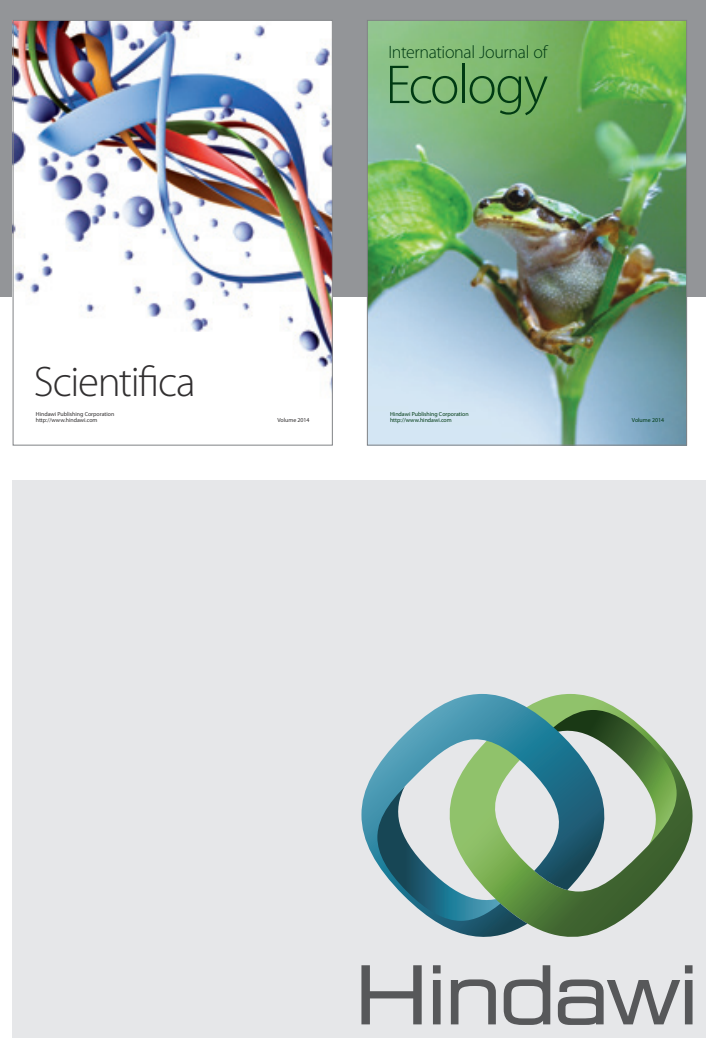

Submit your manuscripts at

https://www.hindawi.com
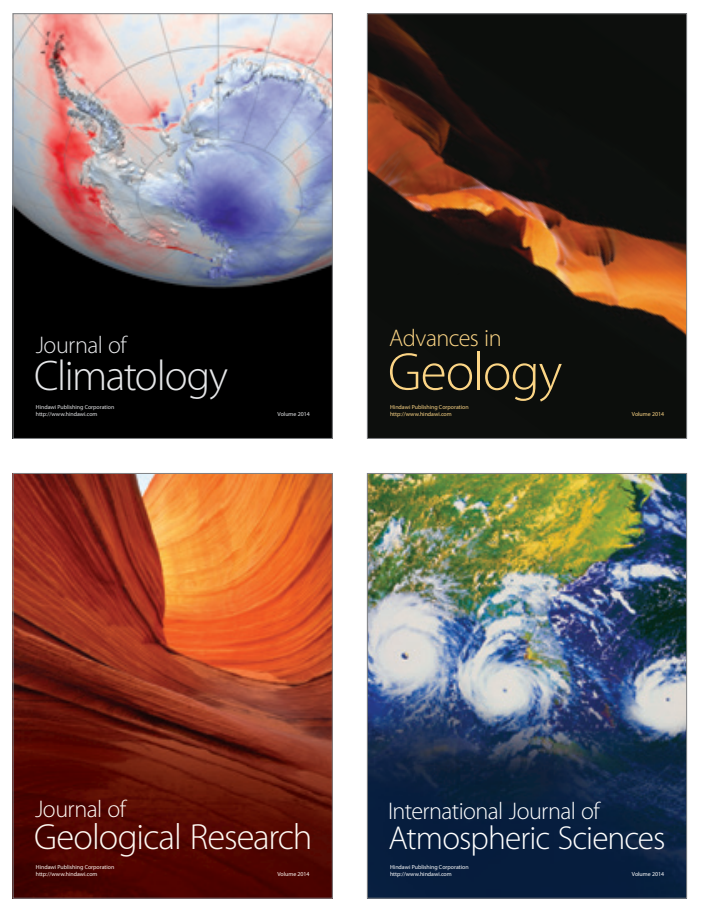

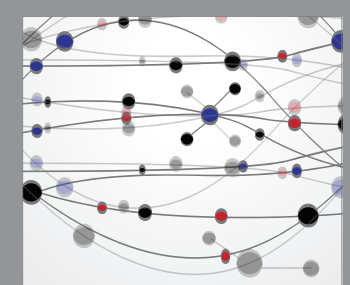

The Scientific

\section{World Journal}
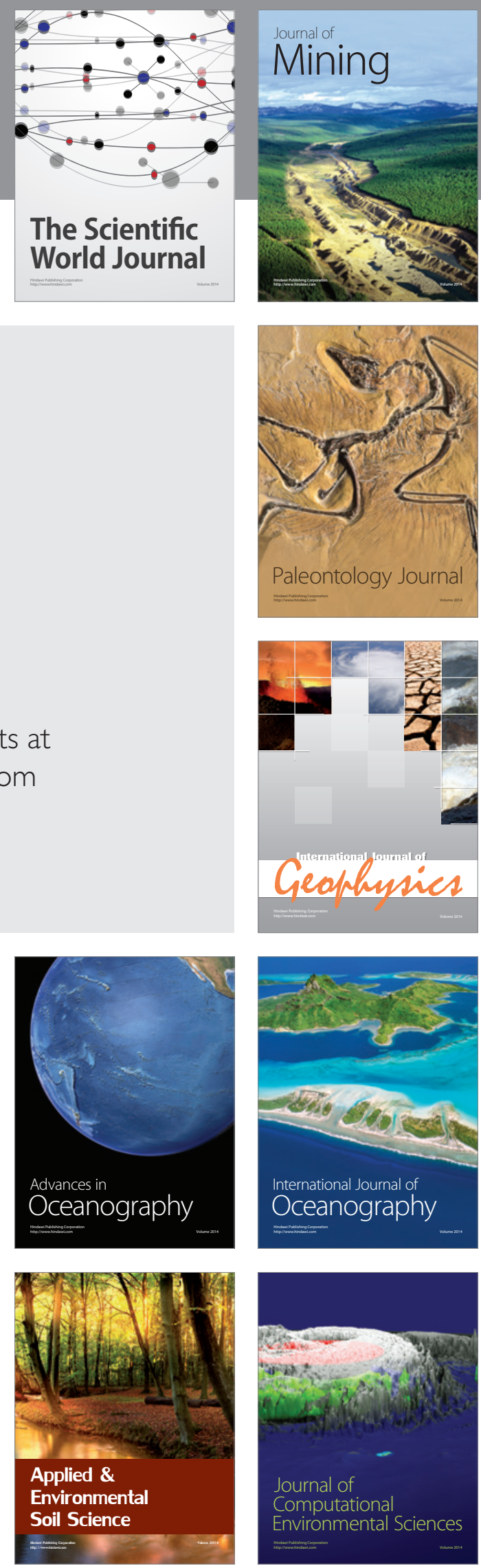